\title{
RAGE binds preamyloid IAPP intermediates and mediates pancreatic $\beta$ cell proteotoxicity
}

\author{
Andisheh Abedini, ${ }^{1}$ Ping Cao, ${ }^{2}$ Annette Plesner, ${ }^{3}$ Jinghua Zhang, ${ }^{1}$ Meilun He, ${ }^{1}$ Julia Derk,, Sachi A. Patil, ${ }^{1}$ Rosa Rosario, ${ }^{1}$ \\ Jacqueline Lonier, ${ }^{1}$ Fei Song, ${ }^{1}$ Hyunwook Koh, ${ }^{4}$ Huilin Li, ${ }^{4}$ Daniel P. Raleigh, ${ }^{2}$ and Ann Marie Schmidt ${ }^{1}$
}

'Diabetes Research Program, Division of Endocrinology, Diabetes and Metabolism, NYU School of Medicine, New York, New York, USA. Department of Chemistry, Stony Brook University, Stony Brook, New York, USA. ${ }^{3}$ Novo Nordisk A/S, Måløv, Denmark. ${ }^{4}$ Division of Biostatistics, Department of Population Health, NYU School of Medicine, New York, New York, USA.

\begin{abstract}
Islet amyloidosis is characterized by the aberrant accumulation of islet amyloid polypeptide (IAPP) in pancreatic islets, resulting in $\beta$ cell toxicity, which exacerbates type 2 diabetes and islet transplant failure. It is not fully clear how IAPP induces cellular stress or how IAPP-induced toxicity can be prevented or treated. We recently defined the properties of toxic IAPP species. Here, we have identified a receptor-mediated mechanism of islet amyloidosis-induced proteotoxicity. In human diabetic pancreas and in cellular and mouse models of islet amyloidosis, increased expression of the receptor for advanced glycation endproducts (RACE) correlated with human IAPP-induced (h-IAPP-induced) $\beta$ cell and islet inflammation, toxicity, and apoptosis. RAGE selectively bound toxic intermediates, but not nontoxic forms of h-IAPP, including amyloid fibrils. The isolated extracellular ligand-binding domains of soluble RAGE (sRAGE) blocked both h-IAPP toxicity and amyloid formation. Inhibition of the interaction between h-IAPP and RAGE by SRAGE, RAGE-blocking antibodies, or genetic RAGE deletion protected pancreatic islets, $\beta$ cells, and smooth muscle cells from $h$-IAPP-induced inflammation and metabolic dysfunction. sRAGE-treated h-IAPP Tg mice were protected from amyloid deposition, loss of $\beta$ cell area, $\beta$ cell inflammation, stress, apoptosis, and glucose intolerance. These findings establish RACE as a mediator of IAPP-induced toxicity and suggest that targeting the IAPP/RAGE axis is a potential strategy to mitigate this source of $\beta$ cell dysfunction in metabolic disease.
\end{abstract}

\section{Introduction}

The misfolding and aggregation of soluble proteins into amyloid fibrils plays a key role in a range of human diseases (1-8). Pancreatic islet amyloidosis is a source of $\beta$ cell proteotoxicity and apoptosis in type 2 diabetes (T2D) $(9,10)$. There are no treatments to prevent this disorder or to preserve $\beta$ cell mass and function $(11,12)$. Pathological aggregation of the endocrine hormone human islet amyloid polypeptide (h-IAPP, also known as amylin) is a key feature in islet amyloidosis. h-IAPP is cosecreted with insulin and plays an adaptive role in metabolism $(6,13-16)$, but in T2D, it aggregates by an unknown mechanism and is deposited as pancreatic islet amyloid plaques associated with reduced $\beta$ cell volume $(2,4,7,8,17,18)$. Aggregation of h-IAPP into amyloid fibrils involves 3 observable stages: Preamyloid oligomers (or prefibrillar intermediates) formed in the lag phase (LP) (first phase) assemble into amyloid fibrils in the growth phase (GP) (second phase), leading to an equilibrium between amyloid fibrils and residual soluble peptide in the saturation phase (SP) (third phase) (Supplemental Figure 1, A and B; supplemental material available online with this article; https:// doi.org/10.1172/JCI85210DS1). Toxic h-IAPP aggregates cause pancreatic $\beta$ cell and islet dysfunction and death, contributing to T2D, islet transplant failure, and, ultimately, cardiovascular and microvascular complications (19-23).

Conflict of interest: The authors have declared that no conflict of interest exists Submitted: October 26, 2015; Accepted: November 17, 2017. Reference information: / Clin Invest. 2018;128(2):682-698. https://doi.org/10.1172/JCl85210
Substantial evidence reveals that both extracellular and intracellular h-IAPP oligomers contribute to islet $\beta$ cell toxicity. Postmortem histological studies of human subjects with T2D show predominantly extracellular pancreatic islet amyloid deposition $(4,6$, 17). Rodents do not develop islet amyloidosis, as rodent IAPP is nonamyloidogenic and nontoxic $(17,24,25)$, but a variety of Tg h-IAPP rodent models have been created that form either extracellular or intracellular islet amyloid, or both (26). Mice that overexpress h-IAPP demonstrate intracellular oligomer formation and defects in autophagy and/or ER stress (27-30), while cultured Tg murine islets expressing physiological levels of h-IAPP do not display ER stress during islet amyloidosis (31). Extracellular h-IAPP oligomers are toxic $(6,19,32-35)$. Findings that h-IAPP secretion is necessary for $\beta$ cell proteotoxicity and amyloid formation (32), studies that show extracellular h-IAPP oligomers can be translocated into $\beta$ cells (36), and receptor-mediated mechanisms of cytotoxicity (33) all support a role for extracellular oligomers in h-IAPP-induced $\beta$ cell and islet pathogenesis. Here, we focus on islet amyloidosis-induced proteotoxicity by extracellular h-IAPP oligomers.

Amyloidogenic h-IAPP induces $\beta$ cell apoptosis in vitro, in rodent models in vivo, and in human T2D (10, 19, 26, 34, 35, 37, 38). Multiple mechanisms of toxicity have been proposed, but there is no consensus about how h-IAPP causes $\beta$ cell damage $(6,17,39)$. Local islet inflammation and the production of cytokines and chemokines have been suggested to contribute to toxicity, as have the disruption of cell membranes by h-IAPP aggregates; impairment of the ER-associated protein degradation/ubiquitin/proteasome (ERAD/ubiquitin/proteasome) pathway and ER stress; defects in autophagy; activation of NADPH-oxidase and consequent oxida- 


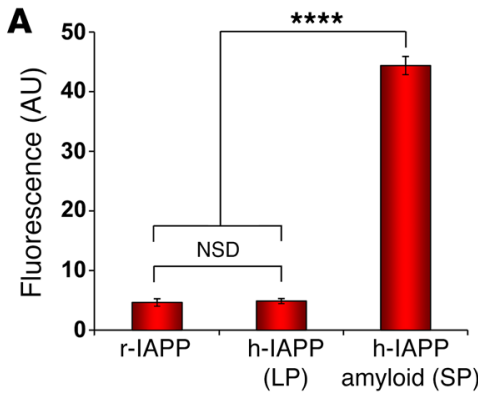

B

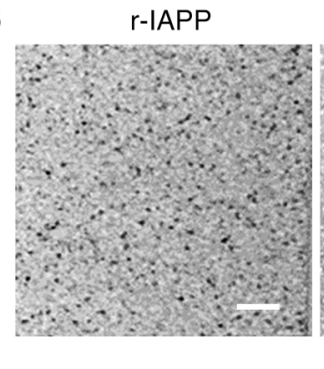

h-IAPP (LP)

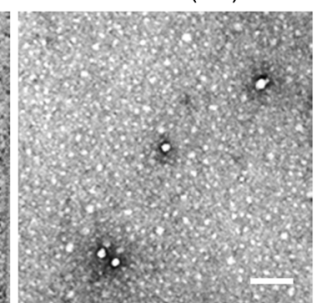

h-IAPP amyloid (SP)

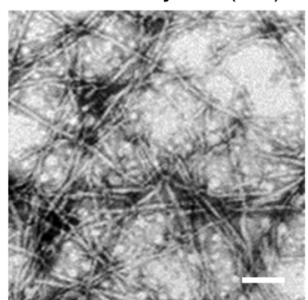

C

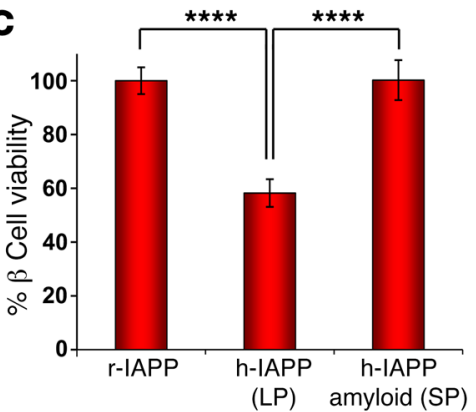

D

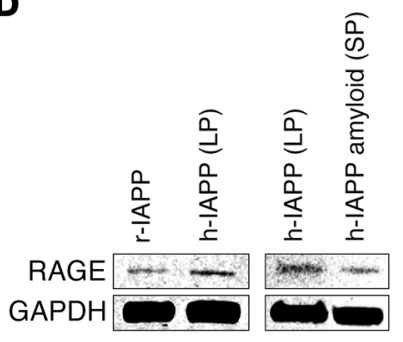

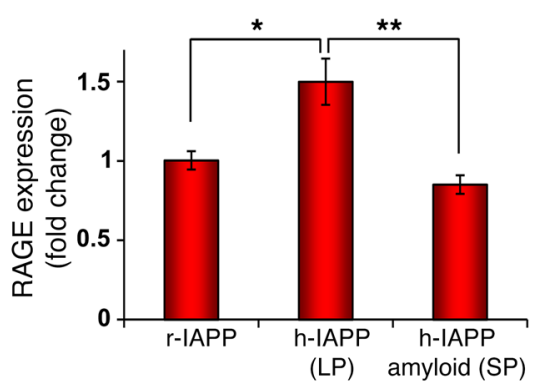

Figure 1. Toxic, preamyloid h-IAPP intermediates upregulate RAGE expression in $\boldsymbol{\beta}$ cells. h-IAPP LP species, SP amyloid fibrils, and r-IAPP aggregates were characterized by (A) thioflavin-T binding, (B) TEM (scale bars: $100 \mathrm{~nm}$ ), and (C) Alamar Blue metabolic assays. (D) WB studies measuring RACE protein. In $\mathbf{C}$ and $\mathbf{D}, \beta$ cells were treated with peptide solutions for 5 hours. RAGE levels in $\mathbf{D}$ were normalized to GAPDH levels and presented as the foldchange relative to r-IAPP-treated $\beta$ cells. The final peptide concentration in cellular assays was $14 \mu \mathrm{M}$. In $\mathbf{D}$, data were taken from 2 distinct WBs in order to accommodate all of the conditions; in both cases, comparisons were made with h-IAPP (LP) species. Data represent the mean \pm SD (thioflavin-T and metabolic assays) and the mean \pm SEM (WBs) of 3 to 4 independent experiments (3-6 technical replicates per experiment). The graphs in A-C represent more than 20 experiments repeated at different times using multiple different preparations of primary peptide stock solutions. NSD, no statistical difference. ${ }^{*} P<0.05,{ }^{* *} P \leq 0.01$, and ${ }^{* * *} P \leq 0.0001$, by 1 -way ANOVA.

tive stress; and receptor-mediated mechanisms linked to the activation of signaling cascades and cleavage of caspases leading to apoptosis $(19,27-30,33-35,38,40-46)$. The available data suggest that h-IAPP exerts its toxic effects on $\beta$ cells by multiple overlapping mechanisms that share common signaling pathways, several of which have yet to be characterized (39). We recently defined the molecular properties of toxic h-IAPP intermediates using timeresolved studies coupling biophysical and biological methods. These studies enable us to investigate proteotoxicity under welldefined conditions (19).

We hypothesized that the receptor for advanced glycation endproducts (RAGE) contributes to h-IAPP-induced islet $\beta$ cell toxicity, as RAGE activates mediators of oxidative stress, inflammation, and apoptosis that are known to be upregulated in h-IAPP-induced cytotoxicity (47). RAGE, a pattern recognition receptor involved in a diverse range of inflammatory diseases including diabetes, engages multiple families of ligands with different properties. The accumulation and binding of ligands upregulate RAGE expression and transduce intracellular signaling, leading to $\beta$ cell and islet stress and apoptosis (48-50). It is not known whether RAGE plays a role in islet amyloidosis-induced $\beta$ cell proteotoxicity. Here, we demonstrate that toxic preamyloid h-IAPP intermediates, but not amyloid fibrils or nontoxic forms of IAPP, bind to RAGE and upregulate $\beta$ cell RAGE expression and that blockade of RAGE inhibits h-IAPP-induced $\beta$ cell and islet inflammation, apoptosis, and glucose intolerance in pancreatic islet amyloidosis. We establish that soluble RAGE (sRAGE) is a highly effective therapeutic agent to prevent both h-IAPP toxicity and amyloid formation in vivo. These findings highlight RAGE as a therapeutic target for $\beta$ cell preservation in metabolic disease and provide critical information for the design of inhibitors of h-IAPP/RAGE interactions.

\section{Results}

RAGE is upregulated in h-IAPP-induced $\beta$ cell and islet proteotoxicity. We have shown that toxic h-IAPP LP intermediates, but not nontoxic h-IAPP amyloid fibrils, induce the production of ROS in INS- $1 \beta$ cells and that this event precedes the detection of metabolic dysfunction (19). If RAGE is a mediator of h-IAPP-induced $\beta$ cell toxicity, then we would expect that toxic h-IAPP LP intermediates would likewise upregulate RAGE expression before detectable loss of $\beta$ cell viability. This was indeed the case. We prepared solutions of h-IAPP LP intermediates, determined that they were prefibrillar by the amyloid-sensitive dye thioflavin- $T$ and by transmission electron microscopy (TEM) (Figure 1, A and B), and incubated them with rat INS-1 $\beta$ cells for a short period of time (1 hour), which does not provoke loss of cell viability (Supplemental Figure $3 \mathrm{~A})$ (19), as well as a longer incubation time (5 hour), which is required to detect metabolic dysfunction in cellular toxicity assays (Figure 1C). The results demonstrated that exogenous h-IAPP LP intermediates upregulated $\beta$ cell RAGE protein expression within 1 hour of peptide incubation on cells, preceding the detection of $\beta$ cell dysfunction (Supplemental Figure 3, A and B). We observed similar results during high-glucose-induced $\beta$ cell stress. INS-1 $\beta$ 
A

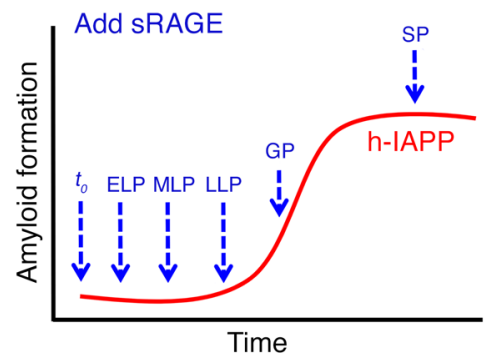

C
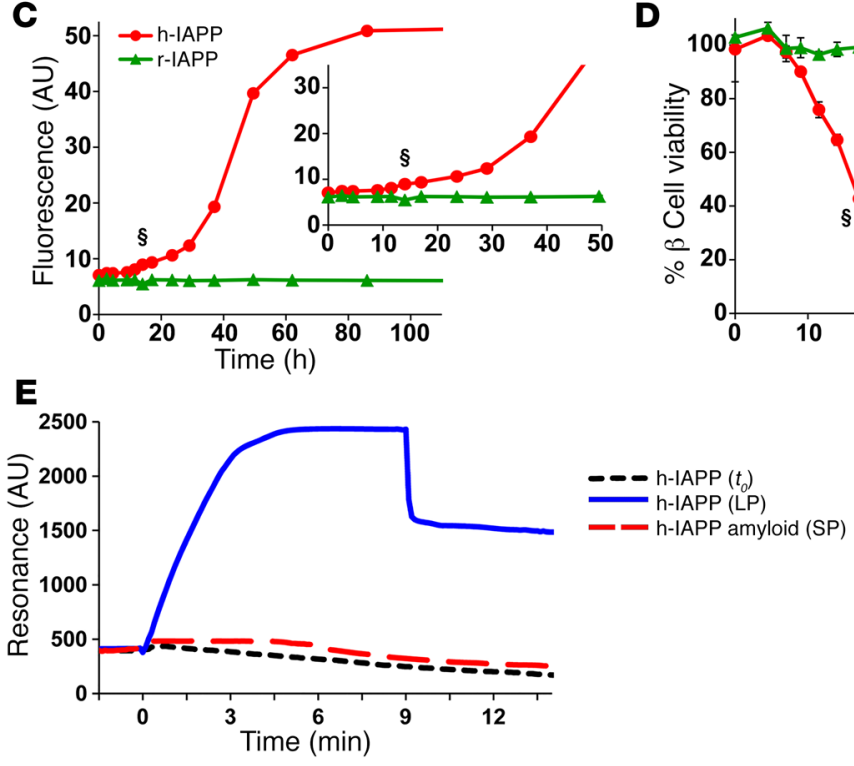

Figure 2. RAGE binds only to the toxic, prefibrillar form of h-IAPP. (A) Schematic diagram showing the design of h-IAPP/sRAGE binding experiments. Blue arrows indicate the time points at which SRAGE was added to h-IAPP over the course of amyloid formation. (B) In the SRAGE Trp fluorescence assays, a 1:1 molar addition of SRAGE to h-IAPP (blue circles) led to a wave of fluorescence quenching that mirrored the wave of h-IAPP toxicity shown in $\mathbf{D}$. No change in fluorescence was observed for SRAGE alone (black squares) or with a 1:1 molar addition of sRAGE to r-IAPP (white triangles). h-IAPP, in the absence of SRAGE (red circles), and r-IAPP, in the absence of SRAGE (green triangles), were used as nonfluorescent controls. (C) ThioflavinT-binding assays, carried out concurrently with sRAGE Trp fluorescence assays and $\beta$ cell metabolic assays, monitored the kinetics of amyloid formation $\left(25^{\circ} \mathrm{C}\right)$ in the peptide solutions used in the experiments shown in B and D. h-IAPP (red circles) and r-IAPP (green triangles). (D) Time-resolved Alamar Blue metabolic assays in INS-1 $\beta$ cells treated with h-IAPP (red circles) or r-IAPP (green triangles) demonstrated that LP intermediates were the most toxic form of h-IAPP. (E) SPR shows that sRAGE bound h-IAPP LP intermediates (blue line) but not $t_{0}$ species (black dashed line) or SP amyloid fibrils (red dashed line). In B-D, the symbol (§) indicates the time point at which the maximum sRAGE Trp fluorescence quenching was observed. The final peptide concentration after transferring peptide aliquots into $\beta$ cell assays was $14 \mu \mathrm{M}$. Data are representative of 3 to 10 independent experiments. Data in $\mathbf{C}$ and $\mathbf{D}$ represent the mean $\pm S D$ of a minimum of 3 to 6 technical replicates per time point. Error bars for some data points are smaller than the size of the symbols.
WT murine pancreatic islets, which showed significant upregulation of RAGE protein expression after treatment with toxic h-IAPP LP intermediates compared with nontoxic r-IAPP (Supplemental Figure 5). These results provide clear evidence that toxic h-IAPP LP intermediates, and not other forms of h-IAPP including amyloid fibrils, upregulate RAGE protein levels in $\beta$ cells and primary islet cells and demonstrate that this initial event precedes $\beta$ cell dysfunction.

$R A G E$ binds specifically to the toxic form of h-IAPP, but not to its nontoxic forms. RAGE is ubiquitously expressed on the surface of cells at low levels in homeostasis, and circulating h-IAPP plays an adaptive role in metabolic regulation. Thus, we expected that RAGE would not bind to the nontoxic functional form of h-IAPP. If RAGE plays a role in islet amyloidosis toxicity, we would also expect that its soluble extracellular ligand-binding domains (sRAGE) would bind to toxic h-IAPP intermediates, but not to nontoxic amyloid fibrils. This is exactly what we observed. We tested the ability of different h-IAPP species that form during amyloid formation to bind sRAGE. In these experiments, h-IAPP amyloid formation was initiated $\left(25^{\circ} \mathrm{C}\right)$ by dissolving lyophilized peptide with buffer (time zero, $t_{0}$ ). sRAGE was added at a 1:1 molar ratio to aliquots of the h-IAPP solution at different time points during amyloid formation (Supplemental Figure 1B and Supplemental Figure 2A), and binding studies were performed concurrently with cellular metabolic assays and TEM.

The hydrophobic patch of sRAGE contains 3 tryptophan (Trp, also known as W) residues, 2 of which, cells incubated at a high glucose concentration $(16.7 \mathrm{mM})$ showed an increase in RAGE protein levels compared with cells cultured at a standard glucose concentration $(11.7 \mathrm{mM})$, which also preceded detectable glucotoxicity (Supplemental Figure 4, A and B). These results are consistent with a role for RAGE in $\beta$ cell stress.

In contrast to the 1 hour incubation period, a longer 5 hour incubation resulted in significant cellular toxicity along with elevated RAGE protein levels (Figure 1, C and D). Treatment of $\beta$ cells with either nontoxic rat IAPP (r-IAPP) or nontoxic h-IAPP amyloid fibrils did not increase RAGE expression (Figure 1, C and D). These findings were recapitulated in studies with isolated
W61 and W72, are partially solvent exposed (Supplemental Figure 2). Ligand binding to this region changes the fluorescent quantum yield of these Trp residues. Neither h-IAPP nor r-IAPP contain any Trp residues. Thus, quenching of sRAGE Trp fluorescence in the presence of IAPP peptides affords an independent probe to monitor IAPP/sRAGE binding (Supplemental Figure 1A and Supplemental Figure 2). Simultaneous Trp fluorescence and thioflavin-T binding studies showed a time-dependent wave of sRAGE Trp fluorescence quenching, with time points of maximum fluorescence loss (denoted by § in Figure 2, B-D) occurring within the LP, indicating that prefibrillar h-IAPP intermediates bound RAGE (Figure 2, B and 

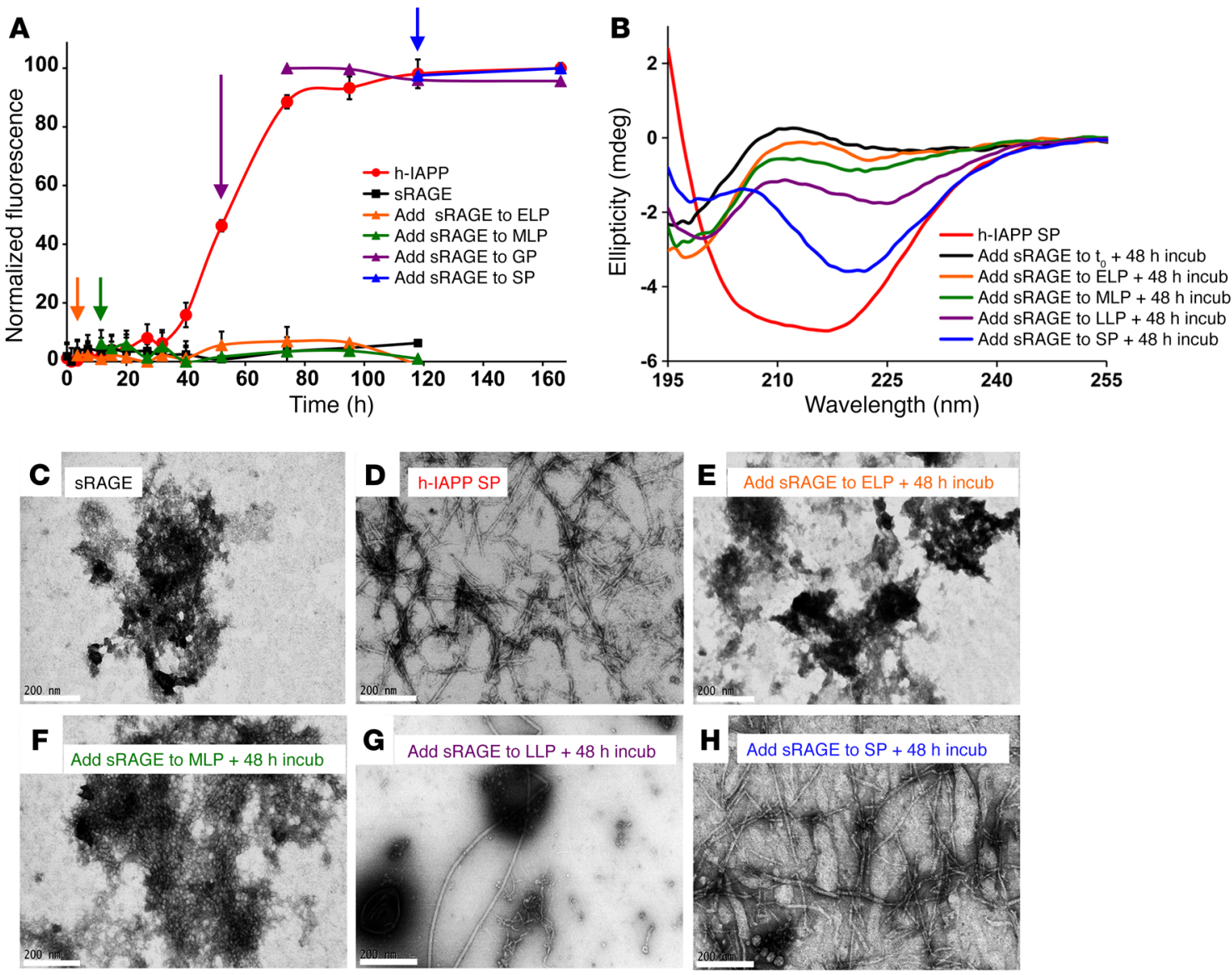

Figure 3. sRAGE targets prefibrillar h-IAPP LP intermediates and inhibits amyloid formation. (A) Thioflavin-T-monitored kinetics of h-IAPP amyloid formation after the addition of sRAGE at different time points $\left(15^{\circ} \mathrm{C}\right)$. Arrows indicate the time points at which sRAGE was added to different kinetic species of h-IAPP: prefibrillar ELP species (orange), prefibrillar MLP species (green), fibrillar GP species (purple), and SP amyloid fibrils (blue). h-IAPP without SRAGE (red) was used as a positive control for amyloid formation. (B) Difference-CD studies showed the effect of sRAGE on h-IAPP secondary structure formation: $t_{0}$ species (black), ELP species (orange), MLP species (green), LLP species (purple), and SP amyloid fibrils (blue). CD spectra of samples were recorded after a 48-hour incubation. h-IAPP readily formed amyloid by itself in the absence of sRAGE (red), but sRAGE inhibited $\beta$-sheet formation when added to h-IAPP at time points before the formation of toxic LP intermediates or when they were present, demonstrating that inhibition by sRAGE was sustained and not transient. The inhibitory effects of sRAGE on h-IAPP $\beta$-sheet formation decreased as it was added to h-IAPP at later time points in the LP. (C-H) Representative TEM images show the morphology of protein species at time points assessed by difference-CD. (C) Amorphous sRAGE alone, (D) h-IAPP SP amyloid fibrils, and the effect of the addition of sRAGE on different h-IAPP kinetic species: (E) ELP species, (F) MLP species, (G) LLP species, and (H) SP amyloid fibrils. Scale bars: $200 \mathrm{~nm}$. The final peptide concentration in biophysical experiments was $20 \mu \mathrm{M}$. Thioflavin-T, CD, and TEM data are representative of 3 to 5 independent experiments. Data in $\mathbf{A}$ represent the mean \pm SD of 3 to 6 technical replicates per time point. Error bars for some data points are smaller than the size of the symbols. incub, incubation.

C). We observed no quenching at $t_{0}$. sRAGE fluorescence quenching diminished during the GP and was not detectable in the SP. The time course for SRAGE Trp fluorescence quenching mirrored the time course for h-IAPP toxicity, confirming that the RAGE-binding h-IAPP intermediates were toxic to $\beta$ cells (19) (Figure 2, B-D). sRAGE did not bind nontoxic r-IAPP at any time point in these studies (Figure 2B). Surface plasmon resonance (SPR) experiments, coupled with TEM studies, confirmed these results. SPR data showed that sRAGE bound to transient preamyloid LP species, but not to $t_{0}$ species or amyloid fibrils (Figure 2E). TEM experiments verified the absence of amyloid fibrils in samples that bound sRAGE (Supplemental Figure 6, A-C). The results of these experiments demonstrate that toxic h-IAPP intermediates are ligands of RAGE.

SRAGE is an inhibitor of amyloid formation by $h$-IAPP. We hypothesized that sRAGE would inhibit h-IAPP amyloid forma- tion, since it selectively binds toxic LP intermediates. We added sRAGE to h-IAPP at different time points over the course of aggregation (Figure 2A) and monitored the effect on the kinetics of amyloid formation using thioflavin-T binding assays, difference circular dichroism (CD), and TEM (Figure 3). Thioflavin-T assays indicate which h-IAPP species sRAGE targets; CD probes the development of secondary structure; and TEM confirms the presence or absence of amyloid. Specifically, we prepared 1 primary stock solution of sRAGE and 1 primary stock solution of h-IAPP, from which aliquots were removed and mixed at various time points during amyloid formation to produce 5 different samples of h-IAPP/sRAGE mixtures: (a) h-IAPP/sRAGE $t_{0}$ species; (b) h-IAPP/sRAGE early LP (ELP) species; (c) h-IAPP/sRAGE midLP (MLP) species; (d) h-IAPP/sRAGE GP species; and (e) h-IAPP/ sRAGE amyloid fibrils in the SP. The kinetics of amyloid forma- 

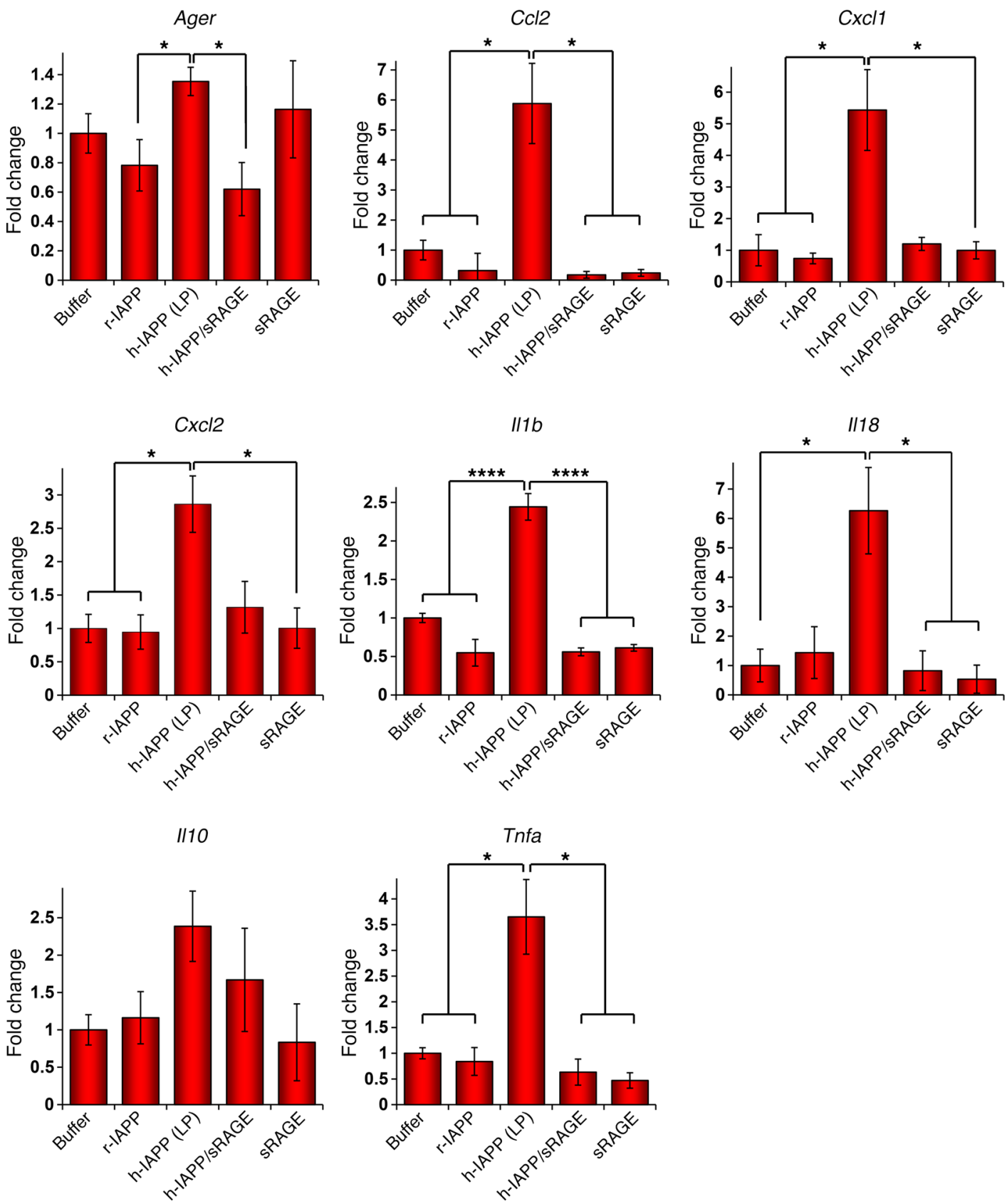

Figure 4. sRAGE inhibits $h$-IAPP-induced inflammatory gene expression in $\beta$ cells. qPCR analysis of INS-1 $\beta$ cells treated (5 hour) with h-IAPP LP intermediates, a 1:1 molar ratio of h-IAPP/sRAGE, sRAGE alone, r-IAPP, or buffer. The final peptide concentration after transferring aliquots into $\beta$ cell assays was $14 \mu \mathrm{M}$. Data represent the mean \pm SEM of 3 to 4 independent experiments (3-9 technical replicates per experiment) and are presented as the fold change relative to buffer-treated $\beta$ cells. ${ }^{*} P<0.05$ and ${ }^{* * *} P \leq 0.0001$, by 1 -way ANOVA.

tion in each sample was then monitored by thioflavin-T binding, difference-CD, and TEM. Aliquots from the original h-IAPP and sRAGE stock solutions were measured at the same time points, serving as control solutions.

A decrease in temperature increases the length of the LP of amyloid formation, facilitating the identification of distinct events in the LP. Thus, we performed the sRAGE/h-IAPP binding experiments at lower temperatures $\left(15^{\circ} \mathrm{C}\right)$ than those conducted in the absence of sRAGE depicted in Figure $2 \mathrm{C}\left(25^{\circ} \mathrm{C}\right)$ to better resolve the effect of adding sRAGE to different h-IAPP LP spe- cies. The data indicate that addition of sRAGE to ELP or MLP species prevented amyloid formation but that sRAGE had no effect when added during the GP or SP (Figure 3A). These data are supported by difference-CD and TEM studies (Figure 3, B-H). The data show that addition of sRAGE to h-IAPP at or before time points of toxic species formation prevented $\beta$-sheet formation, as detected by difference-CD (Figures 3B and Supplemental Figure 7, A-F), and amyloid formation, as detected by TEM (Figure 3, C-F). The data also show that sRAGE had less of an effect when it was added later in the LP (Figure 3, B and G). Thus, sRAGE spe- 

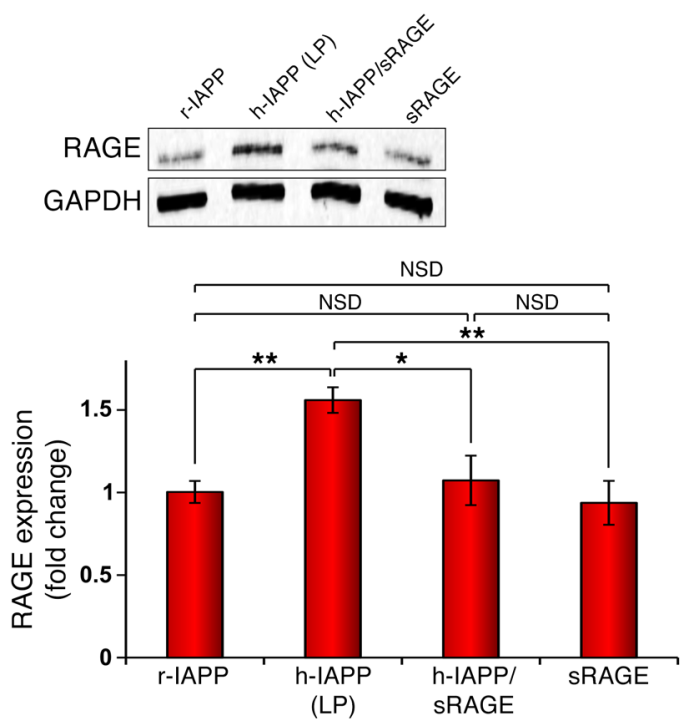

Figure 5. SRAGE inhibits h-IAPP-induced upregulation of RAGE in $\beta$ cells. Representative WB showing RAGE protein levels. WB studies were performed in parallel with the qPCR studies presented in Figure 4 and used identical conditions. RAGE levels were normalized to GAPDH levels. sRAGE-treated cells were washed 3 times with PBS to remove all residual SRAGE before harvesting. The final peptide concentration after transferring aliquots of peptide into $\beta$ cell assays was $14 \mu \mathrm{M}$. Data represent the mean \pm SEM of 3 to 4 independent experiments $(n=3-4$ technical replicates per experiment) and are presented as the fold change relative to r-IAPP-treated cells. ${ }^{*} P<0.05$ and ${ }^{* *} P \leq 0.01$, by 1 -way ANOVA.

cifically targets species that reside early in the LP and blocks amyloid formation by sequestering them and preventing their further assembly into fibrils.

RAGE significantly contributes to h-IAPP-mediated cellular proinflammatory gene expression and cytotoxicity. Our finding that toxic h-IAPP LP intermediates bound RAGE and upregulated $\beta$ cell RAGE expression led us to predict that LP intermediates would modulate inflammatory gene expression and cytotoxicity in cultured $\beta$ cells and muscle cells, as h-IAPP-induced islet cell and cardiomyocyte inflammation have been reported $(40,42,44$, $45,51)$. We also expected that sRAGE would compete with cellsurface RAGE for h-IAPP binding, as it targets toxic LP intermediates and is a competitive inhibitor of ligand binding to cell membrane-bound RAGE. To test this, we used INS- $1 \beta$ cells and primary murine aortic smooth muscle cells (SMCs) as model systems (50, 52). We prepared h-IAPP LP intermediates, a 1:1 molar mixture of h-IAPP/sRAGE, and multiple controls including sRAGE, r-IAPP, and buffer-only solutions. We then characterized each sample and added aliquots to cultured cells for concurrent real-time quantitative PCR (qPCR) and Western blot (WB) studies.

We found that h-IAPP LP intermediates significantly upregulated mRNA transcripts of Ager (the gene encoding RAGE), $C c l 2$, Cxcl1, Cxcl2, Il1b, Il18, and Tnfa, and that treatment of the $\beta$ cells with SRAGE during h-IAPP challenge reduced proinflammatory gene expression. h-IAPP LP intermediates exerted no significant effect on the regulation of antiinflammatory Il10. sRAGE alone, like r-IAPP and buffer, had no independent effect on the regulation of any of the examined inflammatory mediators (Figure 4).
We conducted WB experiments using INS-1 $\beta$ cells in parallel with $q P C R$, thioflavin- $T$, and cell viability studies and observed that the upregulation of $\beta$ cell inflammatory markers and proteotoxicity by h-IAPP LP intermediates was RAGE dependent. WB data in Figure 5 show that preamyloid h-IAPP intermediates significantly increased RAGE protein expression and that blocking h-IAPP/ sRAGE interactions using sRAGE prevented h-IAPP-induced RAGE upregulation. We obtained similar results using RAGEexpressing primary murine aortic SMCs (Supplemental Figure 8A).

We next tested the effect of blocking cellular h-IAPP/sRAGEinteractions on h-IAPP-induced toxicity toward RAGE-expressing murine pancreatic islets, $\beta$ cells, and SMCs using 3 independent strategies: treatment with sRAGE, treatment with RAGE-blocking antibodies (IgGs) that directly block cellular RAGE/ligand interactions, and genetic deletion of RAGE (Ager $/)$. We found that the addition of sRAGE protected pancreatic islet cells, INS-1 $\beta$ cells, and SMCs from h-IAPP-induced metabolic dysfunction (Figure 6 , A and B, and Supplemental Figure 8B). Pretreatment of INS-1 $\beta$ cells with increasing concentrations of anti-RAGE IgG (blue bars, Figure 6C) inhibited metabolic dysfunction by h-IAPP LP intermediates in a dose-dependent manner, unlike what we observed with control IgG (red bars, Figure 6C). Primary pancreatic islets isolated from Ager/ mice (blue bars, Figure 6, D and E) showed significant protection from h-IAPP toxicity compared with islets from agematched RAGE-expressing $\left(\right.$ Ager $\left.^{++}\right)$WT mice (red bars, Figure 6, $\mathrm{D}$ and $\mathrm{E}$ ). We obtained similar results when we added h-IAPP LP intermediates to cultured WT (red bars, Supplemental Figure 8C) versus Ager/- (blue bars, Supplemental Figure 8C) murine aortic SMCs. Together, the results indicate that RAGE plays a key role in mediating h-IAPP toxicity to cells and pancreatic islets.

RAGE is upregulated in hemi_h-IAPP mice in concert with proinflammatory gene expression and $\beta$ cell stress and apoptosis, and treatment with SRAGE ameliorates islet amyloidosis-induced pathology and metabolic dysfunction. To examine the role of RAGE in $\mathrm{h}$-IAPP-induced $\beta$ cell toxicity in vivo and assess the potential efficacy of sRAGE as a therapeutic agent for $\beta$ cell and islet preservation in islet amyloidosis, we used hemizygous Tg mice that express RAGE, overexpress h-IAPP (hemi_h-IAPP mice), and develop $\beta$ cell degeneration and islet amyloidosis pathology but not diabetes $(26,53)$. This prediabetic model decouples the role of RAGE in islet amyloidosis-induced $\beta$ cell perturbation from the multiple other stress-provoking factors that exist in the complex setting of diabetes, including hyperglycemia-mediated formation of other RAGE ligands such as advanced glycation endproducts (AGEs) (49). The slow development of early-stage islet amyloidosis in this model facilitates the gradual accumulation of prefibrillar h-IAPP aggregates, allowing us to test the hypothesis that toxic h-IAPP intermediates cause RAGE-mediated $\beta$ cell defects.

We treated hemi_h-IAPP and WT mice with sRAGE $(100 \mu \mathrm{g} /$ day) or PBS 6 days a week for 10 months to inhibit in vivo h-IAPP/ RAGE interactions. Metabolic characterization confirmed defective $\beta$ cell function in the hemi_h-IAPP mice at 12 months of age, but no diabetes, as previously reported $(26,53)$. The data show that PBS-treated hemi_h-IAPP mice (referred to hereafter as Tg/PBS mice) were mildly but significantly glucose intolerant compared with age-matched and weight-matched WT mice, but no hyperglycemia or significant differences in circulating insulin levels were 
A
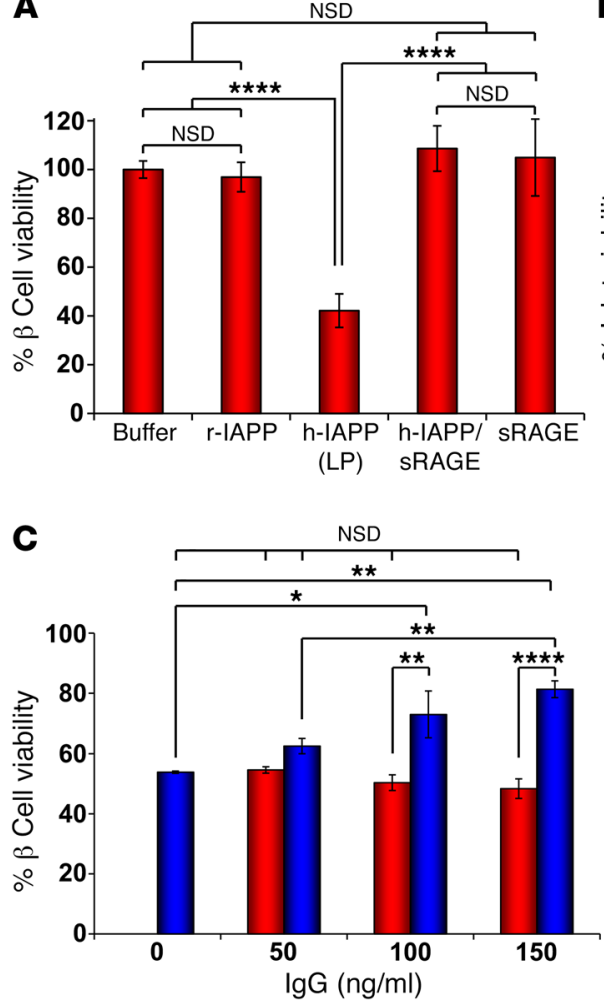

B

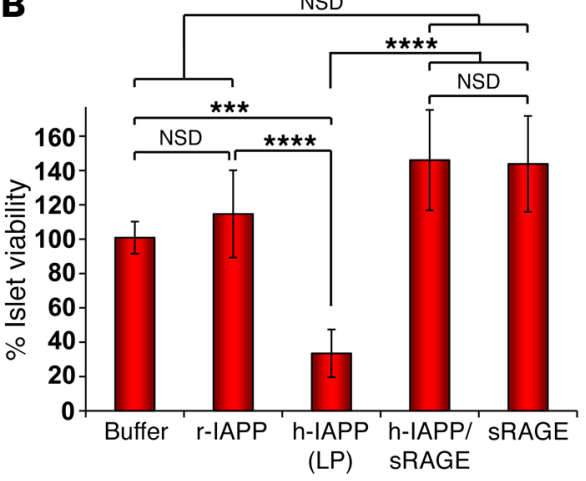

D

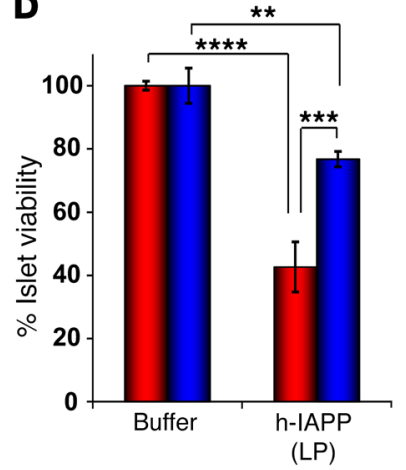

Figure 6. Blocking h-IAPP/RAGE interactions protects $\beta$ cells and primary islets from h-IAPP toxicity. Alamar Blue metabolic assays measuring the viability of $(\mathbf{A})$ rat INS- $1 \beta$ cells and (B) primary WT murine islets after treatment with solutions of h-IAPP LP intermediates, a 1:1 molar mixture of h-IAPP/sRAGE, r-IAPP, sRAGE alone, or buffer. (C) $\beta$ cells pretreated $(2 \mathrm{~h})$ with increasing concentrations of either anti-RAGE IgG (blue) or IgG control (red) before being challenged with toxic h-IAPP LP intermediates. (D) Pancreatic islets isolated from $\mathrm{Ager}^{+/+}$WT (red bars) or Ager/- (blue bars) mice treated with h-IAPP LP species or buffer. (E) Light microscopic images of isolated $\mathrm{Ager}^{+/+}$ WT or $\mathrm{Ager}^{-1-}$ murine pancreatic islets after hand purification. Original magnifcation $\times 20$. The final peptide concentration in viability assays was $14 \mu \mathrm{M}$. Data represent the mean \pm SD of 3 to 7 independent experiments (3-6 technical replicates per experiment). ${ }^{*} P<0.05$ ${ }^{*} P \leq 0.01,{ }^{* *} P \leq 0.001$, and ${ }^{* * *} P \leq 0.0001$, by 1-way or 2-way ANOVA, as appropriate.
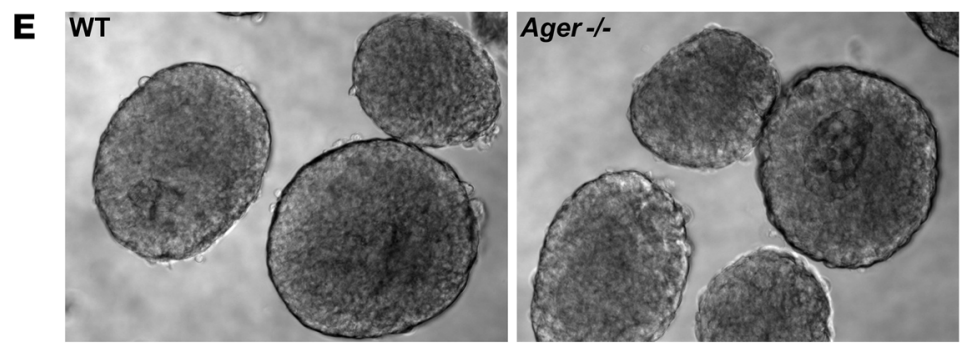

observed (Figure 7, A-E). Quantitative histological analyses of pancreatic tissue revealed an increase in mean islet diameter in $\mathrm{Tg} / \mathrm{PBS}$ mice compared with the WT groups (Figure 7F). Immunofluorescence studies of pancreas sections costained for S100B-insulin or AGEs-insulin confirmed the absence of these RAGE ligands in the $\beta$ cells and islets of both treatment groups of Tg and WT mice, while positive control pancreas sections from diabetic high-fat diet-fed (HFD-fed) WT mice showed AGE and S100B immunoreactivity (Supplemental Figure 9 and Supplemental Figure 10). Treatment of hemi_h-IAPP mice with sRAGE (referred to hereafter as $\mathrm{Tg}$ / sRAGE mice) protected them from islet amyloidosis-induced prediabetic defects in $\beta$ cell function associated with glucose intolerance (Figure 7, A-E), and morphological analyses showed a significantly lower mean islet diameter compared with that observed in islets from $\mathrm{Tg} / \mathrm{PBS}$ mice (Figure $7 \mathrm{~F}$ ). Collectively, the results confirmed that hemi_h-IAPP mice develop $\beta$ cell dysfunction and that sRAGE inhibits h-IAPP toxicity and islet pathology in vivo.

qPCR studies in whole pancreas samples revealed a similar induction pattern of inflammatory mediators in $\mathrm{Tg} / \mathrm{PBS}$ islets in vivo, as was observed in the h-IAPP-treated $\beta$ cells in vitro (Figure 8). $\mathrm{Tg} / \mathrm{sRAGE}$ mice were substantially protected from h-IAPP- induced upregulation of proinflammatory gene expression, as indicated by significantly lower Cxcl 2 and Illb mRNA transcript levels compared with $\mathrm{Tg} / \mathrm{PBS}$ mice and a nonsignificant trend toward lower Ager, Cxcl1, and Il18 gene expression. Upregulation of other inflammatory processes was also observed in $\mathrm{Tg}$ / sRAGE mice, as indicated by a significant increase in Il1O and Tnfa mRNA transcript levels (Figure 8). We observed no change in $\mathrm{Ccl} 2$ levels in Tg/sRAGE mice compared with levels in Tg/PBS mice. These findings confirm in vivo relevance for SRAGE as an inhibitor of islet amyloidosis-induced modulation of inflammatory cytokines and chemokines.

Immunofluorescence studies confirm the upregulation of RAGE immunoreactivity in Tg/PBS islets compared with WT/PBS islets, as well as significant protection of $\mathrm{Tg} / \mathrm{sRAGE}$ mice from islet amyloid deposition, $\beta$ cell stress, and apoptosis. Pancreas sections costained for thioflavin- $S$ and insulin indicated modest amyloid severity in Tg/PBS mice (Figures 9, A and B, and Supplemental Table 1), along with a significant decrease in the mean islet $\beta$ cell area (from $72.4 \% \pm 3.6 \%$ in WT/PBS mice to $59.3 \% \pm$ $2.7 \%$ in $\mathrm{Tg} / \mathrm{PBS}$ mice) (Figure 9C and Supplemental Table 1). In contrast, we found that amyloid deposition in Tg/sRAGE mice 

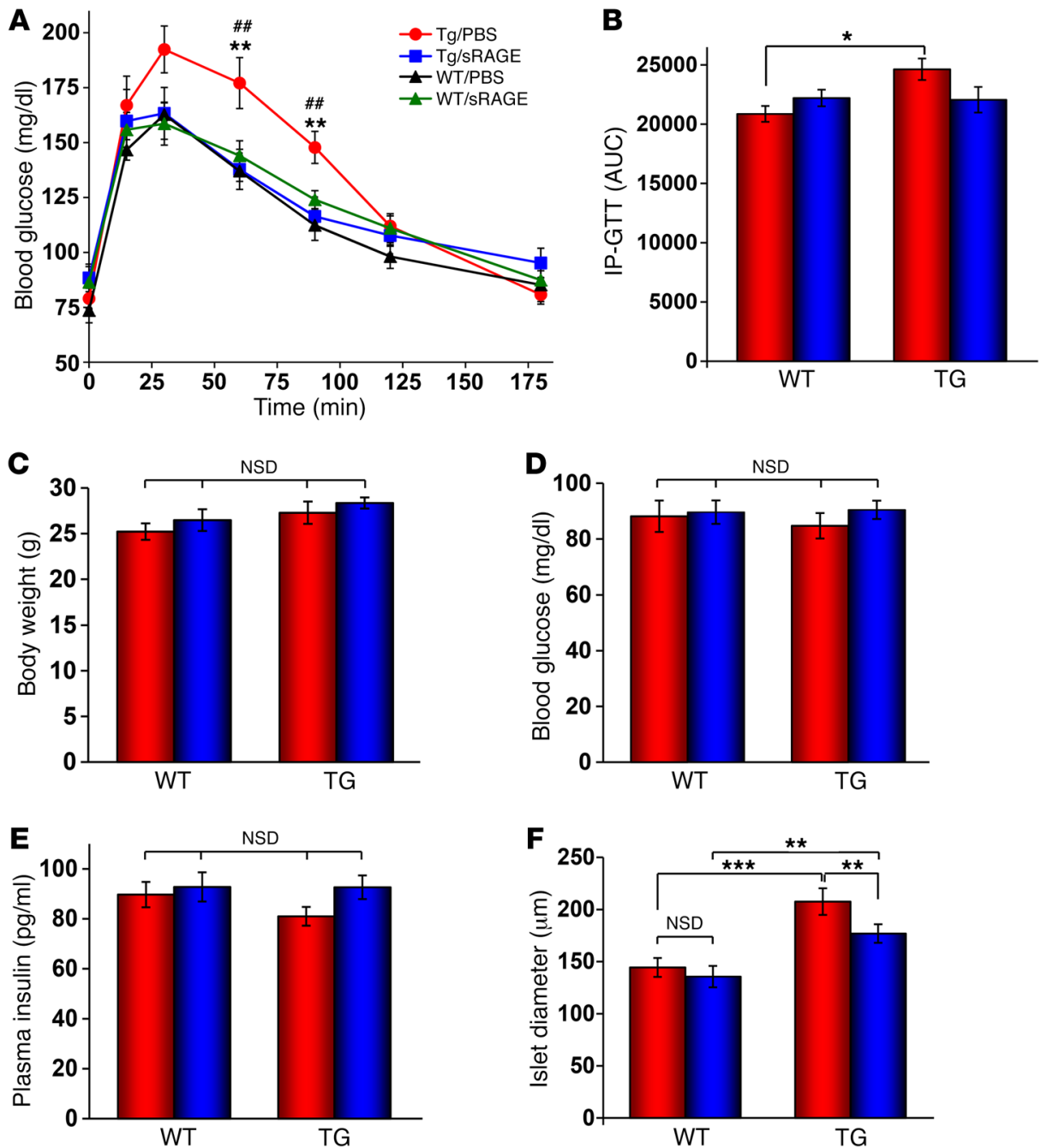

Figure 7. Physiological parameters of mice. The indicated mice were fed a normal chow diet. Treatment of mice with sRAGE (100 $\mu \mathrm{g} / \mathrm{ml}$, i.p.) or PBS was started at 8 weeks of age and continued for 10 months prior to sacrifice at 12 months of age. (A) Glucose intolerance in Tg/PBS mice $(n=10)$ compared with Tg/sRAGE $(n=10)$, WT/PBS $(n=9)$ and WT/sRAGE mice $(n=5) .{ }^{*} P<0.01, \mathrm{Tg} / \mathrm{PBS}$ versus WT/PBS; \#\# $P<0.01, \mathrm{Tg} / \mathrm{PBS}$ versus $\mathrm{Tg} / \mathrm{sRAGE}$. Evaluation of (B) the area under ip-GTT curves up to 180 minutes; (C) body weights ( $n=13$, WT/PBS; $n=8$, WT/sRAGE; $n=15, \mathrm{Tg} / \mathrm{PBS} ; n=13, \mathrm{Tg} / \mathrm{sRAGE}) ;$ (D) fasting blood glucose levels ( $n=13$, WT/PBS;

$n=8$, WT/sRAGE; $n=15$, Tg/PBS; $n=13, \mathrm{Tg}$ / sRACE); and (E) fasting plasma insulin levels $(n=10, \mathrm{WT} / \mathrm{PBS} ; n=8$, WT/sRAGE; $n=12$, Tg/PBS; $n=11$, Tg/sRAGE) for sRAGE-treated (blue) and PBS-treated (red) groups. (F) Histological assessment of the mean islet diameter determined in formalin-fixed, paraffinembedded murine pancreas specimens $(n=3$ mice per group). Data represent the mean \pm SEM (A-E) or the mean \pm SD $(\mathbf{F})$ of the indicated number of mice. ${ }^{*} P<0.05,{ }^{* *} P \leq 0.01$, and ${ }^{* *} P \leq 0.001$, by 1 -way ANOVA. was markedly reduced and that the $\beta$ cell area was preserved to a degree comparable to that observed in WT mice (Figures 9, A-C, Supplemental Figure 11A, and Supplemental Table 1). These findings are consistent with our in vitro data demonstrating inhibition of h-IAPP toxicity and amyloid formation by sRAGE.

Mild islet amyloid deposition in Tg/PBS mice was accompanied by a significant increase in islet $\beta$ cell stress and apoptosis compared with WT/PBS mice, as assessed by costaining with cleaved caspase-3 (CC3) and insulin and triple staining with TUNEL, insulin, and DAPI, respectively (Figure 9, D-G, Supplemental Figure 11, B and C, and Supplemental Table 1). These results are in line with previous studies showing increased $\beta$ cell apoptosis in Tg mouse models overexpressing h-IAPP (26). Treatment of Tg mice with sRAGE led to a significant reduction in $\beta$ cell stress and apoptosis compared with that seen in PBStreated Tg mice (Figure 9, D-G and Supplemental Table 1). We observed no statistically significant differences between sRAGEtreated and PBS-treated WT mice, confirming that sRAGE does not have independent effects, delivers no harm, and offers no additional protection (Figures 9, E and G, Supplemental Figure 11, B and C, and Supplemental Table 1). Pancreas sections from the same mice, costained for RAGE and insulin, showed a significant increase of approximately 1.9 -fold in $\beta$ cell RAGE expres- sion in $\mathrm{Tg} / \mathrm{PBS}$ versus WT/PBS islets (Figure 10, A and B, and Supplemental Table 1).

We observed a direct inverse relationship between islet $\beta$ cell area and $\beta$ cell stress/preapoptosis and apoptosis in Tg/PBS mice (Supplemental Figure 12, A and B, respectively), consistent with previous reports on islet amyloidosis (10). We found that loss of islet $\beta$ cell area also directly correlated with $\beta$ cell RAGE immunoreactivity in Tg/PBS mice (Figure 10C). These data link RAGE with islet amyloidosis-induced $\beta$ cell toxicity and demonstrate that significant $\beta$ cell apoptosis and a loss of $\beta$ cell area do not require extensive islet amyloid deposition or diabetes, consistent with reports in other models (54). Together, the in vivo data support a role for h-IAPP-induced, RAGE-mediated $\beta$ cell and islet defects in prediabetes and confirm that sRAGE is an effective pharmacological agent against islet amyloidosis-induced $\beta$ cell stress and apoptosis.

h-IAPP upregulates $\beta$ cell RAGE expression in human subjects with T2D and islet amyloidosis. We probed the relevance of our findings to human pancreas specimens bearing significant $\beta$ cell stress using T2D and nondiabetic (ND) pancreas samples obtained from the Network for Pancreatic Organ Donors with Diabetes (nPOD). We observed thioflavin- $\mathrm{S}^{+}$islet amyloid plaques in human T2D pancreas sections costained with insulin, 

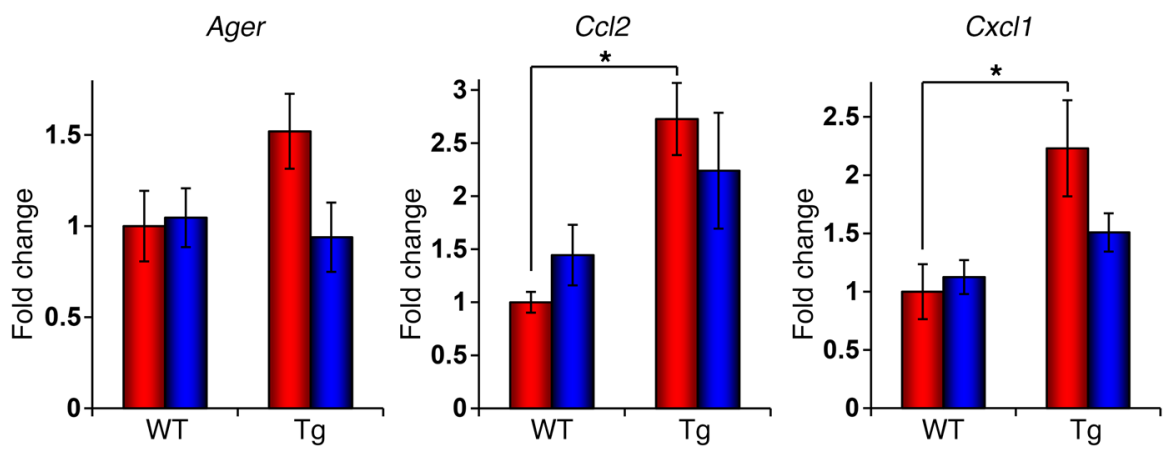

Figure 8. Pancreata of hemi_h-IAPP mice show upregulation of inflammatory genes, which is ameliorated by sRAGE treatment. $\mathrm{QPCR}$ analysis of whole pancreas samples from mice in PBS-treated (red bar) and sRAGE-treated (blue bar) groups. Data represent the mean \pm SEM of 3 to 4 mice per group ( $n=3-9$ technical replicates per mouse) and are presented as the fold change relative to WT/PBS mice. ${ }^{*} P<0.05$ and ${ }^{* *} P \leq 0.01$, by 1 -way ANOVA. Data in the I/18 graph were not normally distributed and are thus reported as the mean \pm SD and were statistically analyzed by nonparametric methods (see Methods).
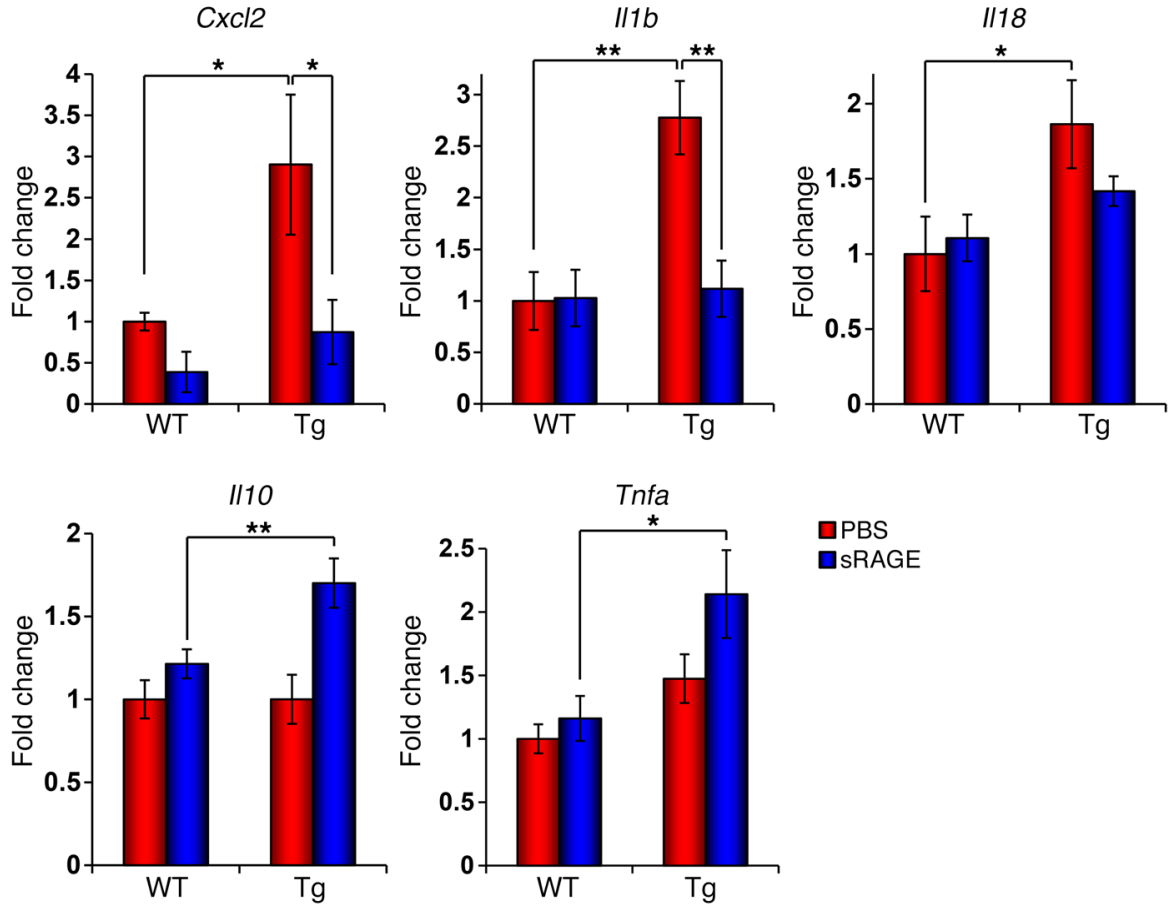

as has been previously reported (10). No amyloid was detected in ND human islets. h-IAPP immunoreactivity in T2D islets colocalized with thioflavin- $\mathrm{S}^{+}$and insulin- islet areas, as well as thioflavin-S ${ }^{-}$and insulin ${ }^{+}$islet areas, suggesting that the antibody detects different forms of h-IAPP (Supplemental Figure 13). We found that islet amyloid deposition in human T2D was accompanied by a significant increase in islet $\beta$ cell RAGE immunoreactivity compared with ND human islets (Figure 11 and Supplemental Table 2). Human T2D RAGE ${ }^{+}$islet areas colocalized with insulin ${ }^{+}$and $\mathrm{h}-\mathrm{IAPP}^{+}$islet areas.

The RAGE staining pattern in human islets appeared different than that observed in murine islets. In both human and murine islets, we detected RAGE expression on the surface of cells. Close examination revealed that RAGE immunoreactivity in murine islets was more intense and punctate and located on insulin ${ }^{+}$, insulin ${ }^{\text {lo }}$, and insulin ${ }^{-}$islet areas, consistent with the ubiquitous expression of RAGE, and was increased on insulin ${ }^{+}$cells in $\mathrm{Tg} /$ PBS mice (Figure 10A). RAGE immunoreactivity in human islets colocalized predominantly with insulin ${ }^{+}$cells in both diabetic and ND islets (Figure 11A). The ring-like pattern suggests that RAGE expression in human islets is more uniform and covers a larger area of the $\beta$ cell surface than is seen in murine islets. The greater RAGE/insulin overlap in human diabetic islets may reflect the fact that these human subjects had longstanding T2D, while the mice were not diabetic. Thus, the differences in staining patterns may well be due to the presence of other glycemia-induced RAGE ligands in diabetic human islets. We confirmed the absence of RAGE ligands (S100B and AGEs) in our murine $\mathrm{Tg} / \mathrm{PBS}$ islets (Supplemental Figures 9 and 10) and their presence in diabetic human islets compared with ND islets (data not shown). Together, the human data support our in vitro, ex vivo, and in vivo findings and indicate that pancreatic islet amyloidosis is associated with the upregulation of $\beta$ cell RAGE expression in T2D.

\section{Discussion}

Our data provide the first evidence to our knowledge that RAGE selectively binds to a distinct, transient population of toxic prefibrillar h-IAPP intermediates and plays a role in h-IAPP-induced cellular perturbation in pancreatic islet amyloidosis (Figure 12). Several lines of evidence strongly support this conclusion. First, RAGE was upregulated in $\beta$ cells prior to cellular metabolic dysfunction, coincident with the upregulation of inflammatory mediators in vitro; in isolated murine islets after challenge with toxic h-IAPP intermediates, leading to loss of islet viability ex vivo; in 
A
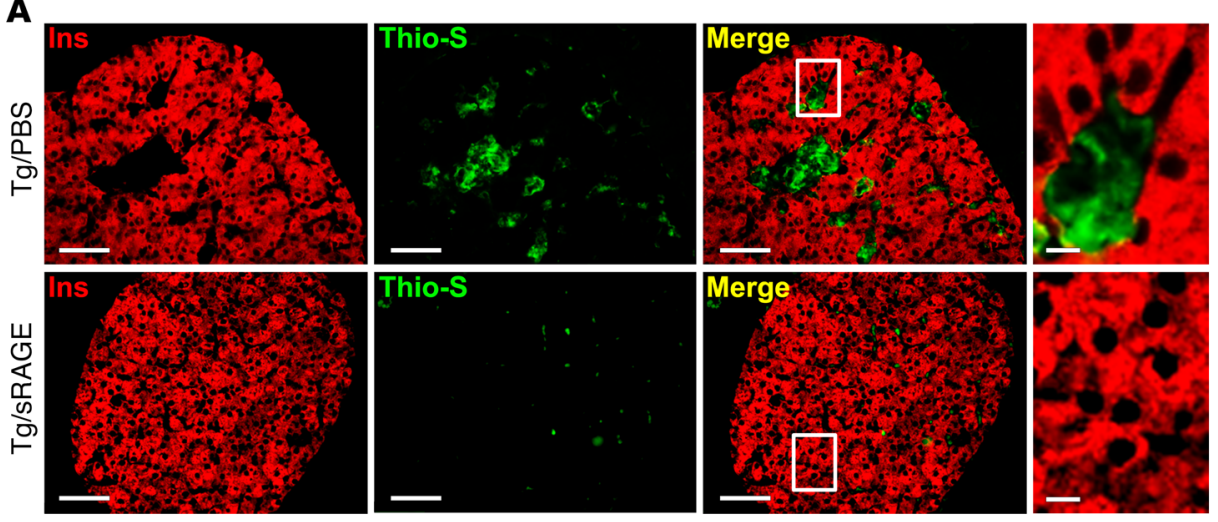

D
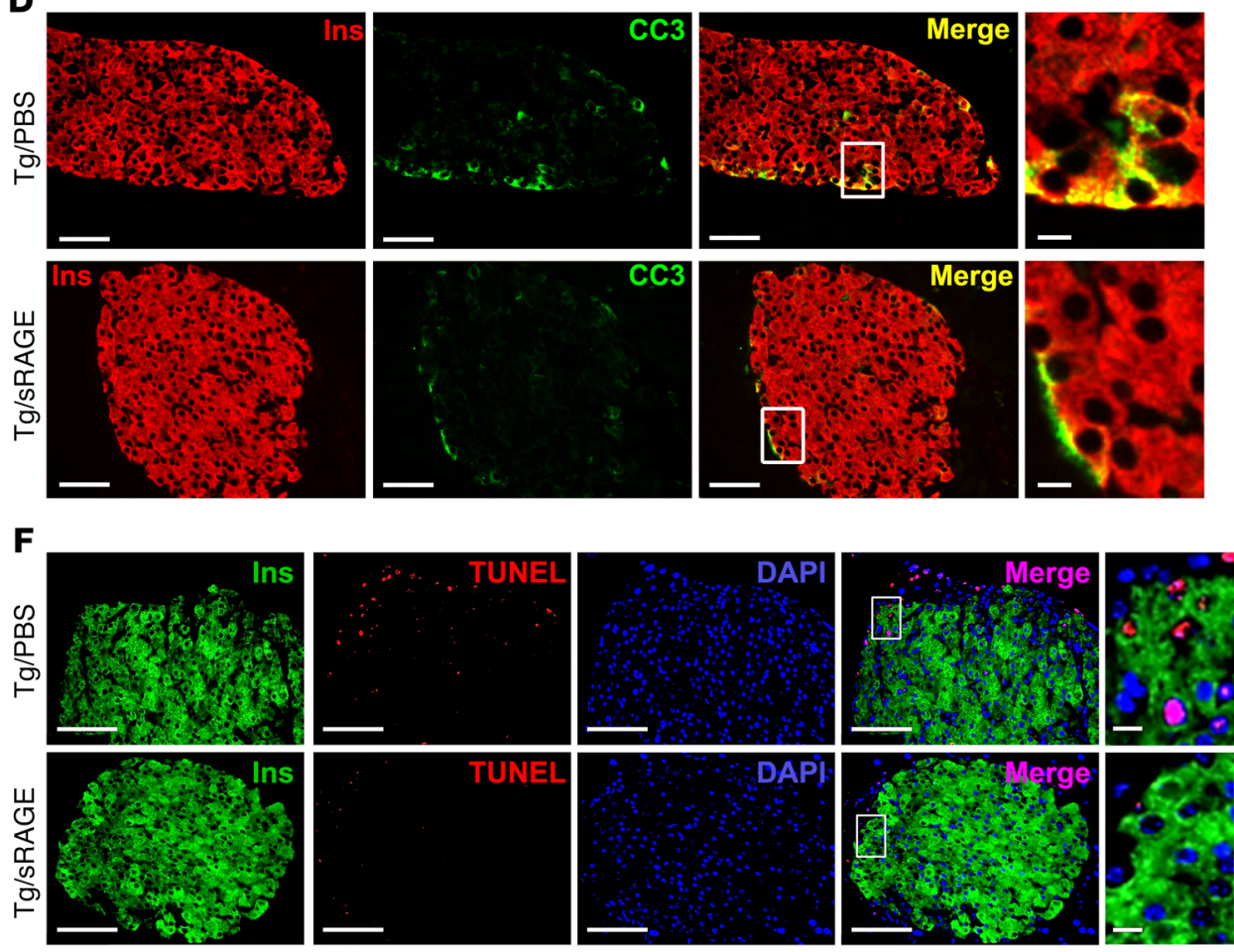
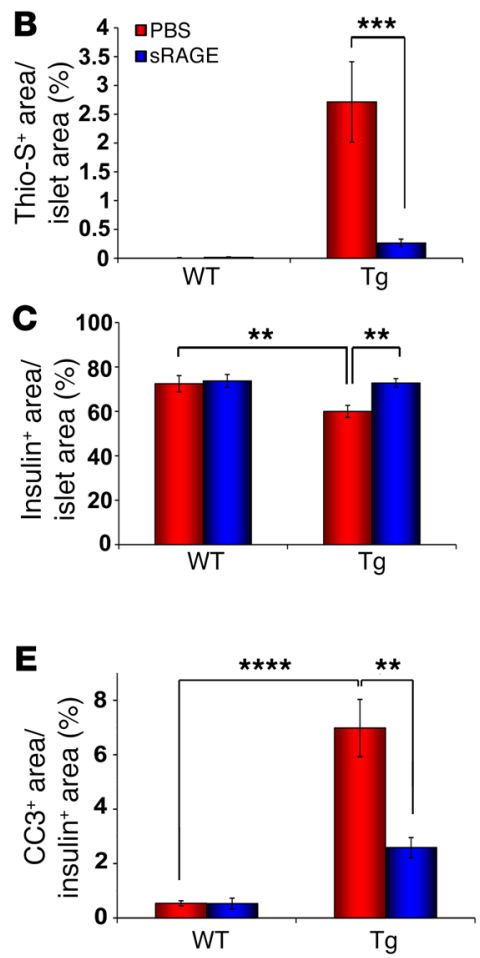

G

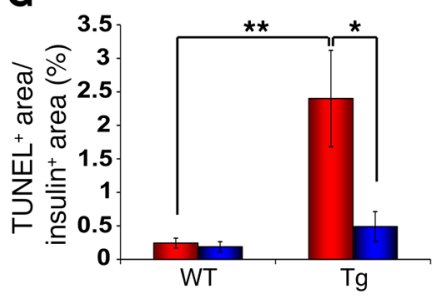

Figure 9. Islet amyloid deposition, $\boldsymbol{\beta}$ cell stress, and apoptosis are suppressed by sRAGE treatment in hemi_h-IAPP mice. (A) Representative murine islets costained in pancreas for insulin (Ins, red) and thioflavin-S (Thio-S, green) show spatial overlap between insulin- (black) and thioflavin-S+ islet areas. Scale bars: $50 \mu \mathrm{m}$. Quantitative immunofluorescence image analysis of (B) islet amyloid severity and (C) islet $\beta$ cell area. (D) Representative murine islets costained in pancreas show colocalization (yellow) of insulin (red) and CC3 (green) immunoreactive islet areas. Scale bars: 50 Hm. (E) Quantitative immunofluorescence image analysis of $\mathrm{CC}^{+}$(stressed/preapoptotic) $\beta$ cell area. (F) Representative murine islets costained in pancreas show colocalization (magenta) of TUNEL+ (red) and DAPI+ (blue) cell nuclei in insulin+ (green) $\beta$ cells. Scale bars: $50 \mu \mathrm{m}$ and $8 \mu \mathrm{m}$ (enlarged insets of $\beta$ cell regions in white boxed areas in $\mathbf{A}, \mathbf{D}$, and $\mathbf{F})$. (G) Quantitative immunofluorescence image analysis of TUNEL ${ }^{+}$(apoptotic) $\beta$ cell area. Data represent the mean \pm SEM of 3 mice per group. ${ }^{*} P<0.05,{ }^{* *} P \leq 0.01$, ${ }^{* *} P \leq 0.001$, and ${ }^{* * * *} P \leq 0.0001$, by 1 -way ANOVA.

a Tg mouse model of early islet amyloidosis with h-IAPP-induced glucose intolerance, loss of islet $\beta$ cell area, and upregulation of inflammatory pancreatic mRNA transcripts in vivo; and in pancreatic islet $\beta$ cells from human subjects with islet amyloidosis and T2D. Second, inhibiting RAGE activity by genetic Ager deletion, using blocking IgGs to prevent cellular h-IAPP/RAGE interactions, or sequestering h-IAPP intermediates with sRAGE to neutralize their toxicity protected cells and pancreatic islets from h-IAPP-induced inflammatory gene expression, metabolic dysfunction, and apoptosis. Third, sRAGE is an inhibitor of both h-IAPP toxicity and amyloid formation in vitro and in vivo. Fourth, RAGE binds only to toxic h-IAPP LP intermediates, while nontoxic forms of IAPP (r-IAPP, h-IAPP $t_{0}$ species, and amyloid fibrils) do not bind RAGE. These observations, together with the findings of other studies that implicate a role for receptor-mediated mechanisms of toxicity, are consistent with extracellular islet amyloid formation but do not exclude the possibility of additional intracellular mechanisms of toxicity $(6,17,33,39)$. 
A
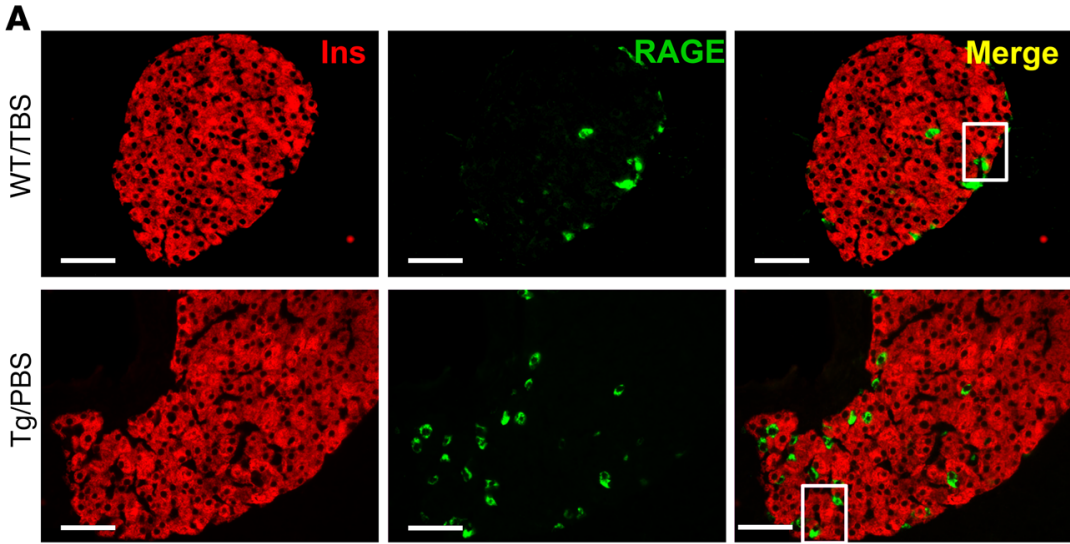
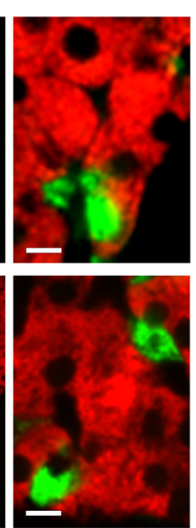

B

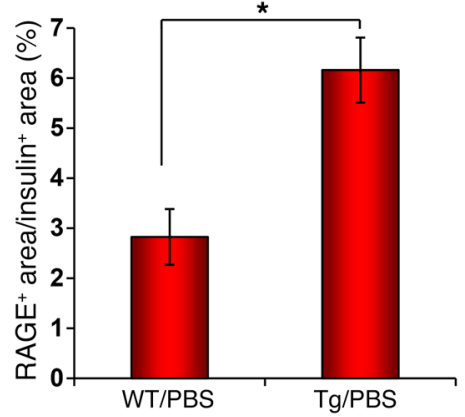

C

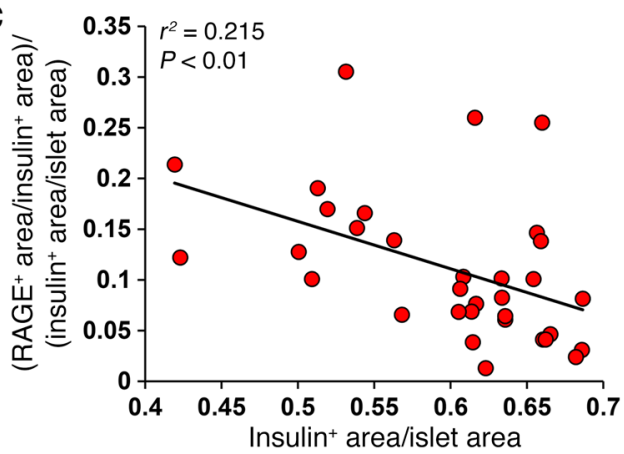

Figure 10. RAGE is upregulated in pancreatic islet amyloidosis. (A) Representative islets in pancreas costained for insulin (red) and RAGE (green) show a significant increase in punctate RAGE $^{+}$areas localized on the surface of $\beta$ cells in Tg/PBS mice compared with WT/PBS mice. Scale bars: $50 \mu \mathrm{m}$ and $8 \mu \mathrm{m}$ (enlarged insets of $\beta$ cell regions in white boxed areas). (B) Quantitative immunofluorescence image analysis of the percentage of RAGE ${ }^{+}$islet area relative to the total insulin $\beta$ cell area. Data represent the mean \pm SEM of 3 mice per group. ${ }^{*} P<0.05$, by 1 -way ANOVA. (C) Linear regression analysis showing that the RAGE ${ }^{+}$islet $\beta$ cell area was associated with loss of $\beta$ cell area in Tg/PBS mice with prediabetes and early-stage islet amyloidosis. $P<0.01 ; r^{2}=0.215$, by Wald test.
The receptor-binding capabilities of IAPP hormones are well documented. The physiological roles of adaptive IAPP are mediated by the IAPP receptor (55). Pathological receptor-mediated mechanisms have also been reported for h-IAPP (33). Our studies show that preamyloid h-IAPP intermediates are ligands of RAGE and define the mode of h-IAPP/RAGE interaction. While multiple overlapping mechanisms probably play a role in IAPP toxicity (17, 39), this work demonstrates that RAGE-mediated processes clearly contribute to and may be one of the pivotal initiating events for many of the downstream cellular pathways associated with h-IAPP toxicity. Our findings are consistent with the hypothesis that many amyloidogenic proteins invoke common mechanisms of cytotoxicity (56) and provide a foundation and blueprint for defining distinct, toxic RAGE-binding entities in other amyloidosis diseases for which RAGE has been postulated to impart pathogenic consequences (57-61).

h-IAPP-induced $\beta$ cell proteotoxicity is linked to local islet inflammatory processes $(40,42,44,45)$. Activation of inflammasomes by h-IAPP aggregates triggers the production of Ill $\mathrm{b}$, suggesting that Ill $b$ enhances h-IAPP toxicity (40). Our in vitro and in vivo studies showing a RAGE-dependent increase in $I l 1 b$ and $I l 18$ mRNA transcripts in $\beta$ cells and in hemi_h-IAPP murine pancreas support these findings. We show that upregulation of the proinflammatory mediators by h-IAPP was prevented by sRAGE. Our studies in hemi_h-IAPP mice demonstrating a significant increase in RAGE immunoreactivity on the surface of insulin ${ }^{+} \beta$ cells and a trend toward increased Ager gene expression in whole pancreas, in parallel with the same cytokines and chemokines, are consistent with previous reports on h-IAPP-expressing Tg mouse models $(44,45)$. While the Ager gene expression signal in whole pan- creas samples was diluted by mRNA extracts from other cell types besides $\beta$ cells, our data still demonstrate a potent in vivo suppression of multiple inflammatory mediators by sRAGE. Interestingly, treatment of hemi_h-IAPP mice with sRAGE did not lead to lower Ccl2 gene expression, suggesting a possible role for infiltration and/or alternative polarization of monocytes and macrophages in $\mathrm{Tg} / \mathrm{sRAGE}$ mice. Further studies are needed to determine the role of infiltrating immune cells in the pathophysiology of islet amyloidosis and the pharmacology of sRAGE. Collectively, these results provide another connection between h-IAPP-induced toxicity and inflammation and suggest that amyloidogenic h-IAPP augments inflammation in pancreatic islet amyloidosis via receptormediated processes, such as recruitment of monocytes/macrophages and other myeloid cells, and activation of the RAGE pathway in $\beta$ cells. These considerations are in line with studies supporting the hypothesis that h-IAPP induces toxicity by multiple and complementary mechanisms $(17,39)$.

Extensive studies have indicated that adaptive IAPP has a physiological role in the regulation of glucose homeostasis via paracrine mechanisms in the pancreatic islets as well as autocrine mechanisms and effects on the central nervous system, and that modulation of IAPP production and/or secretion in pathological settings leads to alterations in glucose metabolism (6). A number of in vivo and in vitro experiments have demonstrated that IAPP has an inhibitory effect on insulin secretion $(62,63)$ and glucagon secretion $(64,65)$. Studies have shown that the decoupling of IAPP and insulin gene expression and secretion in pathological conditions promotes IAPP overproduction and impaired glucose tolerance, but not insulin resistance $(62,66-68)$. The hemi_h-IAPP mouse model used in our studies oversecretes h-IAPP, a process 

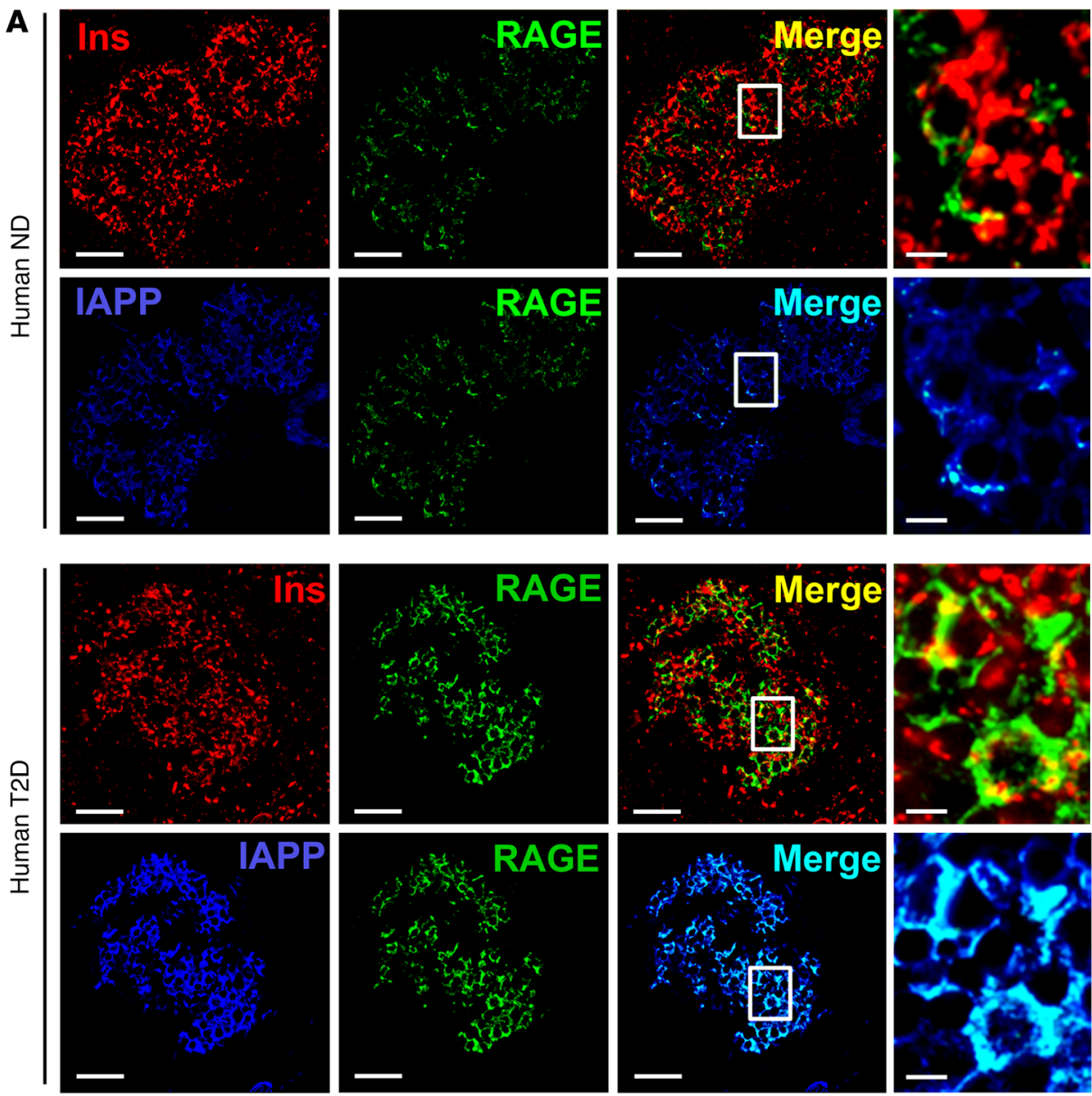

B

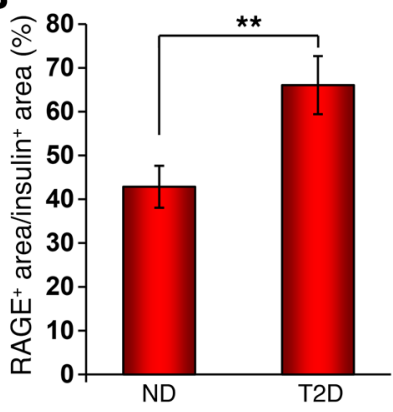

Figure 11. RAGE immunoreactivity in human T2D islets colocalizes with insulin ${ }^{+}$ and h-IAPP+ $\boldsymbol{\beta}$ cells. (A) Representative images of pancreatic islets from T2D (nPOD ID 6124) and ND (nPOD ID 6011) human subjects. Islets were triple stained for insulin (red), h-IAPP (blue), and RAGE (green) and show colocalization (yellow and cyan) of RAGE $^{+}$islet areas with insulin ${ }^{+}$and h-IAPP ${ }^{+}$ $\beta$ cells. Scale bars: $50 \mu \mathrm{m}$ and $8 \mu \mathrm{m}$ (enlarged insets of $\beta$ cell regions in white boxed areas). (B) Quantitative immunofluorescence image analysis shows a significant increase in the RAGE $^{+} \beta$ cell area in T2D compared with ND islets. Data represent the mean \pm SEM of 8 T2D subjects and 7 ND subjects. ${ }^{*} P<0.01$, by 2-tailed Student's $t$ test. that is driven by the insulin II promoter, and recapitulates the h-IAPP hypersecretion observed in glucose intolerance. Previous studies have reported increased blood glucose levels in this $\mathrm{Tg}$ mouse model compared with levels in WT mice (53). We did not observe hyperglycemia in this model but did detect impaired glucose tolerance in the mice at 12 months of age, along with pancreatic inflammation, high levels of $\beta$ cell stress and apoptosis, increased islet size, and a significant decrease in total islet $\beta$ cell area in $\mathrm{Tg} /$ PBS versus WT/PBS mice, consistent with $\beta$ cell compensation in response to increased insulin requirements in mice $(69,70)$. While hyperplasia is not a typical characteristic of most h-IAPP $\mathrm{Tg}$ mouse strains, and the variation in islet sizes in the mice used in our studies made it difficult to conclusively diagnose hyperplasia, as defined by the Department of Health and Human Services National Toxicology Program (71), the observed increase in the size of $\mathrm{Tg} / \mathrm{PBS}$ islets compared with WT control islets was statistically significant $(P \leq 0.001)$. This may be due in part to age and in response to an increased demand for insulin to control impaired glucose tolerance resulting from hypersecretion of h-IAPP. The late onset of observed $\beta$ cell defects suggests that the alteration in glucose metabolism is a slow process in this model. In this case, the mice may have been able to compensate during the period before the onset of amyloidogenesis and the subsequent increase in apoptosis that was detected later at 12 months, which hindered the adaptive increase in $\beta$ cell mass (54). Studies have shown that the total pancreatic $\beta$ cell mass seen in rodents after birth is a balance between $\beta$ cell replication from existing $\beta$ cells, $\beta$ cell production (differentiation) from other sources, and $\beta$ cell apoptosis, and that the formation and maintenance of adult $\beta$ cells depend largely on sources independent of $\beta$ cell duplication (72), as the rate of $\beta$ cell 


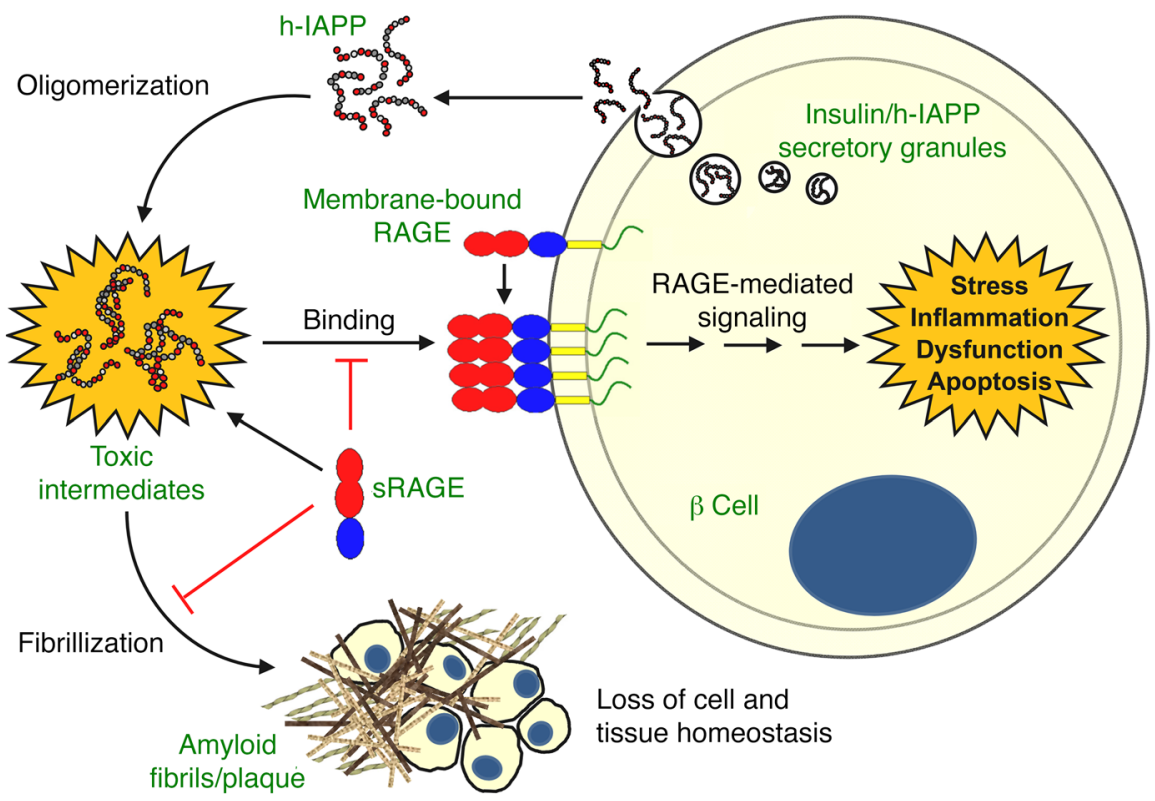

Figure 12. Schematic diagram illustrating a RAGE-mediated mechanism of h-IAPP cytotoxicity and the 2-prong therapeutic advantage of SRAGE. SRAGE has dual beneficial roles as a therapeutic agent for islet amyloidosis, as it (a) binds specifically to the toxic preamyloid form of h-IAPP that induce cellular stress, inflammation, metabolic dysfunction and apoptosis; and (b) prevents further assembly of the toxic intermediates into amyloid fibrils that accumulate into plaques and disrupt cell and tissue homeostasis. Binding of sRAGE to toxic h-IAPP intermediates also averts binding of the intermediates to other cell-surface binding sites besides RAGE, thus significantly blocking cytotoxicity and associated pathological consequences.

replication in rodents declines with age (73). Our in vivo studies were not longitudinal and can only provide a snapshot at the time of sacrifice. Thus, we are limited in our ability to speculate about the rates of $\beta$ cell proliferation, differentiation, or apoptosis other than to say that the rates of $\beta$ cell compensation and apoptosis were probably not linear; rather, they progressively accelerated at different rates and different time points over the 12-month period, with advancing glucose intolerance and islet amyloidosis.

Our in vivo studies confirm the physiological relevance of our in vitro and ex vivo findings and are in line with previous reports that this hemi_h-IAPP mouse model develops $\beta$ cell degeneration and early-stage pancreatic islet amyloidosis in the absence of diabetes (53). This 12-month-old mouse model decouples islet amyloidosisinduced metabolic dysfunction from the additive effects of hyperglycemia and indicates that the onset of islet amyloidosis occurs before the onset of diabetes and is not a consequence of the disease. The data presented in Figure 9, Figure 10, and Supplemental Figure 12, which together demonstrate a direct relationship between the loss of $\beta$ cell area and $\beta$ cell stress, apoptosis, and RAGE expression in $\mathrm{Tg} / \mathrm{PBS}$ mice, and a lack of correlation between these parameters and islet amyloid area, are all normally distributed and statistically significant. The lack of correlation between islet amyloid severity and the extent of $\beta$ cell stress, apoptosis, and loss of $\beta$ cell area is in line with previous reports (54) and supports our other in vitro and in vivo findings that toxic preamyloid h-IAPP intermediates, which gradually form and build up during the slow LP of amyloid formation, are more deleterious than the final thioflavin ${ }^{+}$amyloid fibrils. Our in vivo findings also establish a role for RAGE in islet amyloidosis-induced $\beta$ cell proteotoxicity. Our human pancreas studies show an association between increased $\beta$ cell RAGE expression and h-IAPP amyloidosis in human T2D. Together, our in vivo findings highlight the interaction of RAGE and h-IAPP intermediates as a primary target for $\beta$ cell and islet preservation in metabolic disease.

The administration of sRAGE in vitro and in a murine model of pancreatic islet amyloidosis blocked toxicity, proinflammatory mediators, and amyloid formation; promoted anti-inflammatory processes; and preserved $\beta$ cell area and overall $\beta$ cell and islet morphology. We believe that the dual therapeutic action of sRAGE presents a new paradigm for antiamyloidosis agents. First, sRAGE sequesters and neutralizes h-IAPP intermediates, inhibiting their interaction with RAGE and other cell-surface binding sites, which in turn blocks consequent downstream events leading to toxicity. Second, sRAGE prevents the polymerization of toxic intermediates into amyloid fibrils. While fibrillar h-IAPP is not directly cytotoxic, the accumulation of amyloid plaque causes physical disruption in tissue architecture, elasticity, and homeostasis and thus may contribute to cumulative cellular perturbations.

Our studies define the mode of interaction between toxic h-IAPP species and cellular RAGE. Many RAGE ligands are anionic and are thought to bind to the basic patch on the receptor surface. h-IAPP is cationic and hydrophobic and would thus be expected to repel the basic patch. The data presented here, which indicate a close proximity of h-IAPP with the solvent-exposed sRAGE Trp residues, suggest that toxic h-IAPP intermediates probably bind to the hydrophobic patch on RAGE, highlighting this receptor region as an important site for the engagement of pathogenic species and a potential drug target. This is an important consideration for the design of inhibitors of RAGE activation in pancreatic islet amyloidosis, as the inhibitors of the extracellular RAGE domains that target the basic patch may be ineffective at blocking interactions with distinct hydrophobic ligands, such as h-IAPP.

In summary, we have identified a RAGE-mediated cellular mechanism of h-IAPP-induced $\beta$ cell toxicity in pancreatic islet amyloidosis that precedes the development of hyperglycemia. Further, this work has unveiled an unanticipated dual therapeutic advantage of sRAGE as an inhibitor of both h-IAPP toxicity and amyloid formation itself. We believe these findings fill a critical gap in knowledge and advance our understanding in the field of IAPP biology, as well as across the field of amyloidosis diseases by identifying a new mediator of proteotoxicity that has significant therapeutic implications for $\beta$ cell preservation and mitigation of consequent metabolic dysfunction. 


\section{Methods}

Human pancreas studies. Sections of paraffin-embedded or frozen OCT-embedded pancreas specimens previously prepared from deidentified T2D $(n=8)$ and ND $(n=7)$ human subjects were obtained from nPOD. Tissue IHC-immunofluorescence (IHC-IF) methods were optimized directly in the control human pancreatic tissue. Clinical and immunohistological data for each subject can be found in Supplemental Table 2.

Mouse studies. Hemizygous Tg mice that overexpress the amyloidogenic h-IAPP-coding sequence under the regulation of the rat insulin II promoter 5'-UTR (The Jackson Laboratory) have been described previously $(26,53)$. Male mice were fed a normal chow diet and treated with $100 \mu \mathrm{l}$ i.p. injections of either sRAGE $(100 \mu \mathrm{g} / \mathrm{ml})$ or PBS 6 days a week for 10 months to produce 4 age-matched study groups: Tg/PBS, Tg/sRAGE, WT/PBS, and WT/sRAGE. Body weight, fasting blood glucose, and i.p. glucose tolerance tests (ip-GTTs) were measured over the course of the study, and fasting plasma insulin measurements and analysis of islet size, morphology, and pathology by histological methods were carried out after sacrifice, as described in the Supplemental Methods.

$I H C-I F$. Six sections of formalin-fixed, paraffin-embedded pancreas specimens ( $4 \mu \mathrm{m}$ thick and 30-200 $\mu \mathrm{m}$ apart) were labeled for each marker. All murine and human pancreas sections were stained with primary and secondary antibodies for detection of insulin, amyloid, CC3, TUNEL, RAGE, AGEs, S100B, and IAPP. Images were taken using a Leica fluorescence microscope. Quantitative analysis using MetaMorph LASF imaging software was performed by an investigator blinded to the experimental condition. Detailed methods for histological studies can be found in Supplemental Table 1 and the Supplemental Methods.

Cell culture. The rat insulinoma cell line 832/13 (INS-1 $\beta$ cells) was provided by Christopher Newgard (Duke University School of Medicine, Durham, North Carolina, USA) (74). Murine vascular SMCs were obtained from the aortas of 10-week-old male C57BL/6 mice (The Jackson Laboratory) or Ager ${ }^{-/}$mice (52). Detailed cell culture methods can be found in the Supplemental Methods.

Islet isolation and culture. Pancreatic islets were isolated from anesthetized 12- to 18-week-old C57BL/6 mice (The Jackson Laboratory) or Ager/- mice (52) according to institutional guidelines, hand purified, and cultured in supplemented RPMI 1640 medium, as described in the Supplemental Methods.

Protein preparation. IAPP peptides were prepared as previously described (19) or purchased from the KECK Foundation at Yale University (New Haven, Connecticut, USA). Human sRAGE was prepared via a baculovirus expression system using Sf9 cells (Clontech, Invitrogen, Thermo Fisher Scientific) (75), as described in the Supplemental Methods.

Amyloid formation assays. Amyloid formation reactions were initiated as previously described (19) and were monitored using thioflavin-T binding assays. Aliquots were removed from stock solutions at various time points over the course of amyloid formation and further characterized by difference-CD and TEM.

Toxicity assays. INS-1 $\beta$ cells were seeded at a density of 30,000 cells per well in 96-well plates 24 hours prior to experiments and incubated for 1 or 5 hours with aliquots of peptide solutions or controls. SMCs were seeded at a density of 300,000 cells per well in 6-well plates 36 hours before experiments, switched to serum-free DMEM 12 hours before experiments, and incubated for 10 hours with aliquots from peptide stock solutions or controls. Hand-purified islets of the same size and number (25 islets/well in 96-well plates) were incubated for 3 to 5 hours with peptide solutions or controls. Final peptide concentrations in cellular and islet assays were $14 \mu \mathrm{M}$. Cell and islet viability was assessed by Alamar Blue metabolic assays (76) and light microscopy, as previously described (19). Values were calculated relative to those of control cells or islets treated with buffer or r-IAPP. Data from islet experiments were normalized to the total number of islets per well. $\beta$ Cell viability data represent numerous $(>20)$ experiments carried out at different times by different laboratory members using multiple preparations of peptide stock solutions.

Light microscopy. Changes in cell and islet morphology were examined by light microscopy as an additional method of evaluating viability. Images were captured using an Olympus BX-61 light microscope.

RAGE blockade assays. Blocking antibodies were produced at the Pocono Rabbit Farm \& Laboratory, Inc. using previously described methods (77). INS- $1 \beta$ cells were plated at a density of 30,000 cells per well in 96-well plates 24 hours before experiments. Cells were pretreated (2.5 hours) with either rabbit anti-human RAGE IgG or rabbit nonimmune IgG prior to challenge (5 hours) with toxic h-IAPP intermediates $(14 \mu \mathrm{M})$. Cell viability was measured by Alamar Blue metabolic assays.

RNA isolation and qPCR. Total cellular RNA and tissue RNA were isolated from $\beta$ cells, SMCs, or pancreas specimens using the RNeasy Plus Mini Kit or RNeasy Fibrous Tissue Mini Kit (QIAGEN). The quality of RNA was determined by measurement of a 260:280 ratio. RNA $(1 \mu \mathrm{g})$ was reverse transcribed to cDNA with MultiScribe Reverse Transcriptase (Applied Biosystems). Real-time qPCR was performed using the TaqMan method $\left(50^{\circ} \mathrm{C}\right.$ for $2 \mathrm{~min}, 95^{\circ} \mathrm{C}$ for $10 \mathrm{~min}$, and 40 cycles of $95^{\circ} \mathrm{C}$ for 15 seconds and $60^{\circ} \mathrm{C}$ for $1 \mathrm{~min}$ ) with premade Ager, Ccl2, Cxcl1, Cxcl2, Il1b, Il18, Il1O, Tnfa, and Vcam1 primers (Life Technologies, Thermo Fisher Scientific). Relative mRNA contents were normalized according to the expression of 18S rRNA using the $\Delta \Delta \mathrm{Ct}$ method. qPCR was performed using an Applied Biosystems 7500 Real-time PCR machine.

$W B$ analysis. Proteins (25-60 $\mu$ g per lane) isolated from $\beta$ cells or murine pancreatic islets were separated on a $4 \%-12 \%$ Bis-Tris NuPAGE gel (Bio-Rad) and transferred onto a PVDF membrane. Membranes were probed overnight $\left(4^{\circ} \mathrm{C}\right)$ with the following primary antibodies: rabbit anti-RAGE (1:1,000; GeneTex; GTX23611) and anti-mouse GAPDH (1:1,000; Abcam; ab8245), followed by the following secondary antibodies ( 1 hour, $25^{\circ} \mathrm{C}$ ): IRDye $800 \mathrm{EW}$ goat anti-rabbit IgG (1:10,000; LI-COR; 925-32211) for detection of RAGE, and IRDye 680RD goat anti-mouse IgG (1:25,000; LI-COR; 925-68070) for detection of GAPDH. Protein signals were quantified using the Odyssey Infrared Imaging System (LI-COR; model 9120). RAGE protein signals were normalized to GAPDH protein signals in the same lane.

TEM. Samples $(4 \mu \mathrm{l})$ were placed on a carbon-coated, 200-mesh copper grid and negatively stained with saturated uranyl acetate (Electron Microscopy Sciences). The samples were imaged with a Philips CM12 or a FEI BioTwinG2 transmission electron microscope.

Thioflavin-T binding assays. Aliquots $(100 \mu \mathrm{l})$ of peptide solutions were added to 96 -well plates containing $8 \mu \mathrm{l}$ of a $1 \mathrm{mM}$ thioflavin- $\mathrm{T}$ solution (Sigma-Aldrich). The final solution conditions contained 15 or $25 \mu \mathrm{M}$ peptide, $20 \mathrm{mM}$ Tris $\mathrm{HCl}$, and $74 \mu \mathrm{M}$ thioflavin- $\mathrm{T}$ ( $\mathrm{pH}$ 7.4). Fluorescence was measured using a Beckman Coulter DTX880 plate reader (excitation, $445 \mathrm{~nm}$; emission, $485 \mathrm{~nm}$ ). Additional information can be found in the Supplemental Methods. 
Far UV CD. Far UV CD was performed using an Applied Photophysics spectrophotometer. Aliquots $(300 \mu \mathrm{l})$ were transferred from amyloid formation assays to a $0.1 \mathrm{~cm}$ quartz cuvette within a few minutes prior to data collection. Spectra were recorded over a range of 190 to $260 \mathrm{~nm}$, and CD spectra represented the average of 5 repeats. Background spectra were subtracted. In difference-CD experiments, the spectra for solutions of sRAGE alone, which were collected at the same time as respective h-IAPP/sRAGE mixtures, were subtracted from the spectra of h-IAPP/sRAGE mixtures. The samples contained $20 \mathrm{mM}$ tris $\mathrm{HCl}$ ( $\mathrm{pH} 7.4)$.

Trp fluorescence and SPR. sRAGE Trp fluorescence (280 nm excitation; $350 \mathrm{~nm}$ emission) was measured using a Photon Technology International instrument. The signal was an average of 20 reads over $20 \mathrm{sec}-$ onds ( $2.5 \mathrm{~nm}$ bandwidth and 1-second integration time). In SPR studies, sRAGE was immobilized on the sensor chip, and the interaction of different h-IAPP species with sRAGE was measured using a GE Healthcare SPR instrument. The final peptide concentrations were $20 \mu \mathrm{M}$ h-IAPP or $\mathrm{r}$-IAPP and $20 \mu \mathrm{M}$ sRAGE in $20 \mathrm{mM}$ Tris- $\mathrm{HCl}\left(\mathrm{pH} 7.4,25^{\circ} \mathrm{C}\right)$.

Statistics. Data analysis was carried out in collaboration with biostatisticians using appropriate statistical analysis methods determined by the distribution type and sample size of the data sets. Normally distributed data, as judged by the Shapiro-Wilk normality test, are presented as either mean \pm SEM or mean \pm SD of $n$ independent experiments (as reported in each figure legend), as appropriate. Data that did not pass the Shapiro-Wilk normality test [Figure 8 (Il18 panel only) and Supplemental Figure 4] are presented as mean \pm SD. For multiple-group comparisons, normally distributed data were analyzed by one-way or two-way ANOVA, as appropriate, followed by post hoc Tukey HSD for pairwise comparisons, or post hoc paired $t$-test for a pre-selected set of group comparisons. For two-group comparisons, normally distributed data were first analyzed by the F-test to compare variances between two groups, followed by two sample 2 -tailed $t$-test with equal or unequal variance. Data that did not pass the Shapiro-Wilk normality test were assessed by the Kruskal-Wallis rank sum test followed by Dunn's post hoc group comparison test. Data were corrected for multiple comparisons using the BenjaminiHochberg multiple comparison correction; an adjusted $P$ value of $<0.05$ was considered significant. The significance of the linear regression analyses in correlation studies was determined by the Wald test; a $P$ value of $<0.05$ was considered significant. For paired group comparisons, ANOVA with post hoc test results of $P<0.1$ but $>0.05$ were considered non-significant trends.

Study approval. All animal procedures were approved by the IACUC of New York University and performed in accordance with $\mathrm{NIH}$ animal care guidelines. All deidentified human studies were IRB exempt, as determined by the NYU School of Medicine IRB. nPOD is a research organization based in Gainesville, FL, that operates under the approval of the University of Florida's IRB. This approval allows nPOD to work with Organ Procurement Organizations (OPOs) to obtain tissue from organ donors in the U.S. Adults who have registered while alive to become an organ donor upon their passing are considered to have granted consent for organ recovery for transplant and research. If the donor is a minor child, or is an adult who has not independently registered, the OPO approaches the legal next-of-kin for consent. The 58 OPOs in the U.S. operate regionally, and each have a version of a patient consent form. OPOs within the U.S. are members of the Organ Procurement and Transplantation Network (OPTN) and are overseen by the United Network for Organ Sharing (UNOS).

\section{Author contributions}

AA designed the research, conducted experiments, analyzed data, and wrote the manuscript. PC prepared critical reagents and assisted with experiments. AP, JZ, MH, JD, SAP, and JL assisted with in vitro experiments. RR and FS assisted with in vivo experiments. HK and HL analyzed data. DPR and AMS designed and directed research, analyzed data, and wrote the manuscript.

\section{Acknowledgments}

We thank Rehana Akter, Ling-Hsien Tu, and Hui Wang (Stony Brook University) for assistance with IAPP preparation; Vivek Rai (NYU School of Medicine) for assistance with SPR studies; Carmen Hurtado del Pozo (NYU School of Medicine) for assistance with WB studies; Luis Chiriboga (NYU School of Medicine) for assistance with IHC studies; Latoya Woods (NYU School of Medicine) for assistance with preparation of the figures; Christopher Newgard at Duke University for providing the rat INS-1 $\beta$ cells; and Donald Landry at Columbia University Medical Center (New York, New York, USA) for allowing us to use his BiaCore for SPR studies. This research was performed with the support of the nPOD, a collaborative type 1 diabetes research project sponsored by the Juvenile Diabetes Research Foundation International. The organ procurement organizations partnering with nPOD to provide research resources are listed on the nPOD's website (www.jdrfnpod.org/our-partners. php). This work was supported by grants from the American Heart Association (17SDG33410350, to AA) and the NIH (HL60901, to AMS; GM078114, to DPR; P32CA016087, S10OD01058, and S10OD018338, to the NYU Experimental Pathology Research Laboratory [EPRL]). This work was also supported in part by Research Funds, the Diabetes Research Program at NYU Langone Medical Center, and by a Laura and Isaac Perlmutter Cancer Center support grant to NYU EPRL.

Address correspondence to: Andisheh Abedini, Diabetes Research Program, NYU School of Medicine, 550 First Avenue, Smilow Research Center, Room 910, New York, New York, 10016, USA. Phone: 212.263.9477; Email: andisheh.abedini@nyumc.org.
1. Chiti F, Dobson CM. Protein misfolding, functional amyloid, and human disease. Annu Rev Biochem. 2006;75:333-366.

2. Cooper GJ, Willis AC, Clark A, Turner RC, Sim $\mathrm{RB}$, Reid KB. Purification and characterization of a peptide from amyloid-rich pancreases of type 2 diabetic patients. Proc Natl Acad Sci U S A. 1987;84(23):8628-8632.
3. Eisenberg D, Jucker M. The amyloid state of proteins in human diseases. Cell. 2012;148(6):1188-1203.

4. Hull RL, Westermark GT, Westermark P, Kahn SE. Islet amyloid: a critical entity in the pathogenesis of type 2 diabetes. JClin Endocrinol Metab. 2004;89(8):3629-3643.

5. Kahn SE, Andrikopoulos S, Verchere CB. Islet amyloid: a long-recognized but underappreciated pathological feature of type 2 diabetes. Diabetes. 1999;48(2):241-253.

6. Westermark P, Andersson A, Westermark GT. Islet amyloid polypeptide, islet amyloid, and diabetes mellitus. Physiol Rev. 2011;91(3):795-826.

7. Westermark P, Wernstedt C, Wilander E, Hayden DW, O’Brien TD, Johnson KH. Amyloid fibrils in 
human insulinoma and islets of Langerhans of the diabetic cat are derived from a neuropeptidelike protein also present in normal islet cells. Proc Natl Acad Sci U S A. 1987;84(11):3881-3885.

8. Clark A, et al. Islet amyloid, increased A-cells, reduced B-cells and exocrine fibrosis: quantitative changes in the pancreas in type 2 diabetes. Diabetes Res. 1988;9(4):151-159.

9. Lorenzo A, Razzaboni B, Weir GC, Yankner BA. Pancreatic islet cell toxicity of amylin associated with type-2 diabetes mellitus. Nature. 1994;368(6473):756-760.

10. Jurgens $C A$, et al. $\beta$-cell loss and $\beta$-cell apoptosis in human type 2 diabetes are related to islet amyloid deposition. Am J Pathol. 2011;178(6):2632-2640.

11. Ashcroft FM, Rorsman P. Diabetes mellitus and the beta cell: the last ten years. Cell. 2012;148(6):1160-1171.

12. Halban PA, et al. $\beta$-cell failure in type 2 diabetes: postulated mechanisms and prospects for prevention and treatment. JClin Endocrinol Metab. 2014;99(6):1983-1992.

13. Hieronymus L, Griffin S. Role of amylin in type 1 and type 2 diabetes. Diabetes Educ. 2015; 41(1 Suppl):47S-56S.

14. Li Z, Kelly L, Heiman M, Greengard P, Friedman JM. Hypothalamic amylin acts in concert with leptin to regulate food intake. Cell Metab. 2015;22(6):1059-1067.

15. Kahn SE, et al. Evidence of cosecretion of islet amyloid polypeptide and insulin by beta-cells. Diabetes. 1990;39(5):634-638.

16. Lutz TA. Control of energy homeostasis by amylin. Cell Mol Life Sci. 2012;69(12):1947-1965.

17. Akter R, et al. Islet amyloid polypeptide: Structure, function, and pathophysiology. J Diabetes Res. 2016;2016:2798269.

18. Westermark P. Quantitative studies on amyloid in the islets of Langerhans. Ups J Med Sci. 1972;77(2):91-94.

19. Abedini A, et al. Time-resolved studies define the nature of toxic IAPP intermediates, providing insight for anti-amyloidosis therapeutics. Elife. 2016;5:e12977.

20. Potter KJ, et al. Islet amyloid deposition limits the viability of human islet grafts but not porcine islet grafts. Proc Natl Acad Sci U S A. 2010;107(9):4305-4310.

21. Bram Y, et al. Apoptosis induced by islet amyloid polypeptide soluble oligomers is neutralized by diabetes-associated specific antibodies. Sci Rep. 2014;4:4267.

22. Despa S, et al. Hyperamylinemia contributes to cardiac dysfunction in obesity and diabetes: a study in humans and rats. Circ Res. 2012;110(4):598-608.

23. Westermark GT, Westermark P, Berne C, Korsgren $\mathrm{O}$. Widespread amyloid deposition in transplanted human pancreatic islets. $N$ Engl J Med. 2008;359(9):977-979.

24. Westermark P, Engstrom U, Johnson KH, Westermark GT, Betsholtz C. Islet amyloid polypeptide: pinpointing amino acid residues linked to amyloid fibril formation. Proc Natl Acad Sci U S A. 1990;87(13):5036-5040.

25. Kapurniotu A. Amyloidogenicity and cytotoxicity of islet amyloid polypeptide. Biopolymers. 2001;60(6):438-459.
26. Matveyenko AV, Butler PC. Islet amyloid polypeptide (IAPP) transgenic rodents as models for type 2 diabetes. ILAR J. 2006;47(3):225-233.

27. Huang CJ, et al. High expression rates of human islet amyloid polypeptide induce endoplasmic reticulum stress mediated beta-cell apoptosis, a characteristic of humans with type 2 but not type 1 diabetes. Diabetes. 2007;56(8):2016-2027.

28. Kim J, et al. Amyloidogenic peptide oligomer accumulation in autophagy-deficient beta cells induces diabetes. JClin Invest. 2014;124(8):3311-3324.

29. Shigihara N, et al. Human IAPP-induced pancreatic beta cell toxicity and its regulation by autophagy. J Clin Invest. 2014;124(8):3634-3644.

30. Rivera JF, et al. Human-IAPP disrupts the autophagy/lysosomal pathway in pancreatic beta-cells: protective role of p62-positive cytoplasmic inclusions. Cell Death Differ. 2011;18(3):415-426.

31. Hull RL, Zraika S, Udayasankar J, Aston-Mourney K, Subramanian SL, Kahn SE. Amyloid formation in human IAPP transgenic mouse islets and pancreas, and human pancreas, is not associated with endoplasmic reticulum stress. Diabetologia. 2009;52(6):1102-1111.

32. Aston-Mourney K, Hull RL, Zraika S, Udayasankar J, Subramanian SL, Kahn SE. Exendin-4 increases islet amyloid deposition but offsets the resultant beta cell toxicity in human islet amyloid polypeptide transgenic mouse islets. Diabetologia. 2011;54(7):1756-1765.

33. Park YJ, et al. Deletion of Fas protects islet beta cells from cytotoxic effects of human islet amyloid polypeptide. Diabetologia. 2012;55(4):1035-1047.

34. Zhang S, Liu J, Dragunow M, Cooper GJ. Fibrillogenic amylin evokes islet beta-cell apoptosis through linked activation of a caspase cascade and JNK1. J Biol Chem. 2003;278(52):52810-52819.

35. Casas S, Gomis R, Gribble FM, Altirriba J, Knuutila S, Novials A. Impairment of the ubiquitin-proteasome pathway is a downstream endoplasmic reticulum stress response induced by extracellular human islet amyloid polypeptide and contributes to pancreatic beta-cell apoptosis. Diabetes. 2007;56(9):2284-2294.

36. Trikha S, Jeremic AM. Distinct internalization pathways of human amylin monomers and its cytotoxic oligomers in pancreatic cells. PLoS One. 2013;8(9):e73080.

37. Matveyenko AV, Butler PC. Beta-cell deficit due to increased apoptosis in the human islet amyloid polypeptide transgenic (HIP) rat recapitulates the metabolic defects present in type 2 diabetes. Diabetes. 2006;55(7):2106-2114

38. Zraika S, et al. Oxidative stress is induced by islet amyloid formation and time-dependently mediates amyloid-induced beta cell apoptosis. Diabetologia. 2009;52(4):626-635.

39. Abedini A, Schmidt AM. Mechanisms of islet amyloidosis toxicity in type 2 diabetes. FEBS Lett. 2013;587(8):1119-1127.

40. Masters SL, et al. Activation of the NLRP3 inflammasome by islet amyloid polypeptide provides a mechanism for enhanced IL-1beta in type 2 diabetes. Nat Immunol. 2010;11(10):897-904.

41. Park YJ, et al. The role of caspase- 8 in amyloidinduced beta cell death in human and mouse islets. Diabetologia. 2014;57(4):765-775.

42. Westwell-Roper C, et al. IL-1 blockade attenuates islet amyloid polypeptide-induced proinflammatory cytokine release and pancreatic islet graft dysfunction. JImmunol. 2011;187(5):2755-2765.

43. Gurlo T, et al. CHOP contributes to, but is not the only mediator of, IAPP induced beta-cell apoptosis. Mol Endocrinol. 2016;30(4):446-454.

44. Meier DT, Morcos M, Samarasekera T, Zraika S, Hull RL, Kahn SE. Islet amyloid formation is an important determinant for inducing islet inflammation in high-fat-fed human IAPP transgenic mice. Diabetologia. 2014;57(9):1884-1888.

45. Westwell-Roper CY, Ehses JA, Verchere CB. Resident macrophages mediate islet amyloid polypeptide-induced islet IL-1beta production and betacell dysfunction. Diabetes. 2014;63(5):1698-1711.

46. Janson J, Ashley RH, Harrison D, McIntyre S, Butler PC. The mechanism of islet amyloid polypeptide toxicity is membrane disruption by intermediate-sized toxic amyloid particles. Diabetes. 1999;48(3):491-498.

47. Wautier MP, Chappey O, Corda S, Stern DM, Schmidt AM, Wautier JL. Activation of NADPH oxidase by AGE links oxidant stress to altered gene expression via RAGE. Am J Physiol Endocrinol Metab. 2001;280(5):E685-E694.

48. Zhu Y, et al. Inhibition of the receptor for advanced glycation endproducts (RAGE) protects pancreatic beta-cells. Biochem Biophys Res Commun. 2011;404(1):159-165.

49. Costal F, et al. Dual effect of advanced glycation end products in pancreatic islet apoptosis. Diabetes Metab Res Rev. 2013;29(4):296-307.

50. Lee BW, Chae HY, Kwon SJ, Park SY, Ihm J, Ihm SH. RAGE ligands induce apoptotic cell death of pancreatic beta-cells via oxidative stress. Int $J$ Mol Med. 2010;26(6):813-818.

51. Liu M, et al. Hyperamylinemia Increases IL-1beta Synthesis in the Heart via Peroxidative Sarcolemmal Injury. Diabetes. 2016;65(9):2772-2783.

52. Toure F, et al. Formin mDia1 mediates vascular remodeling via integration of oxidative and signal transduction pathways. Circ Res. 2012;110(10):1279-1293.

53. Couce M, et al. Treatment with growth hormone and dexamethasone in mice transgenic for human islet amyloid polypeptide causes islet amyloidosis and beta-cell dysfunction. Diabetes. 1996;45(8):1094-1101.

54. Butler AE, Janson J, Soeller WC, Butler PC. Increased beta-cell apoptosis prevents adaptive increase in beta-cell mass in mouse model of type 2 diabetes: evidence for role of islet amyloid formation rather than direct action of amyloid. Diabetes. 2003;52(9):2304-2314.

55. Muff R, Buhlmann N, Fischer JA, Born W. An amylin receptor is revealed following co-transfection of a calcitonin receptor with receptor activity modifying proteins-1 or -3 . Endocrinology. 1999;140(6):2924-2927.

56. Bucciantini M, et al. Inherent toxicity of aggregates implies a common mechanism for protein misfolding diseases. Nature. 2002;416(6880):507-511.

57. Schmidt AM, Sahagan B, Nelson RB, Selmer J, Rothlein R, Bell JM. The role of RAGE in amyloid-beta peptide-mediated pathology in Alzheimer's disease. Curr Opin Investig Drugs. 2009;10(7):672-680. 
58. Sturchler E, Galichet A, Weibel M, Leclerc E, Heizmann CW. Site-specific blockade of RAGE$\mathrm{Vd}$ prevents amyloid-beta oligomer neurotoxicity. J Neurosci. 2008;28(20):5149-5158.

59. Yan SD, et al. RAGE and amyloid-beta peptide neurotoxicity in Alzheimer's disease. Nature. 1996;382(6593):685-691.

60. Yan SD, et al. Receptor-dependent cell stress and amyloid accumulation in systemic amyloidosis. Nat Med. 2000;6(6):643-651.

61. Sasaki N, et al. Advanced glycation end products (AGE) and their receptor (RAGE) in the brain of patients with Creutzfeldt-Jakob disease with prion plaques. Neurosci Lett. 2002;326(2):117-120.

62. Cluck MW, Chan CY, Adrian TE. The regulation of amylin and insulin gene expression and secretion. Pancreas. 2005;30(1):1-14.

63. Young A. Historical background. Adv Pharmacol. 2005;52:1-18.

64. Gedulin BR, Rink TJ, Young AA. Dose-response for glucagonostatic effect of amylin in rats. Metabolism. 1997;46(1):67-70.

65. Wang F, Adrian TE, Westermark GT, Ding X, Gasslander T, Permert J. Islet amyloid polypeptide tonally inhibits beta-, alpha-, and delta-cell secretion in isolated rat pancreatic islets. Am J
Physiol. 1999;276(1 Pt 1):E19-24.

66. Eriksson J, et al. Early metabolic defects in persons at increased risk for non-insulin-dependent diabetes mellitus. NEngl JMed.1989;321(6):337-343.

67. Eriksson J, Nakazato M, Miyazato M, Shiomi K, Matsukura S, Groop L. Islet amyloid polypeptide plasma concentrations in individuals at increased risk of developing type 2 (non-insulindependent) diabetes mellitus. Diabetologia. 1992;35(3):291-293.

68. Stridsberg M, Berne C, Sandler S, Wilander E, Oberg K. Inhibition of insulin secretion, but normal peripheral insulin sensitivity, in a patient with a malignant endocrine pancreatic tumour producing high amounts of an islet amyloid polypeptidelike molecule. Diabetologia. 1993;36(9):843-849.

69. Alonso LC, et al. Glucose infusion in mice: a new model to induce beta-cell replication. Diabetes. 2007;56(7):1792-1801.

70. Khadra A, Schnell S. Development, growth and maintenance of beta-cell mass: models are also part of the story. Mol Aspects Med. 2015;42:78-90.

71. Pancreatic Islets - Hyperplasia. National Toxicology Program.https://ntp.niehs.nih.gov/nnl/endocrine/ pancreatic_islets/hyperpl/index.htm. Updated July 24, 2014. Accessed Novemeber 22, 2017.
72. Manesso E, et al. Dynamics of beta-cell turnover: evidence for beta-cell turnover and regeneration from sources of beta-cells other than beta-cell replication in the HIP rat. Am J Physiol Endocrinol Metab. 2009;297(2):E323-E330.

73. Teta M, Long SY, Wartschow LM, Rankin MM, Kushner JA. Very slow turnover of beta-cells in aged adult mice. Diabetes. 2005;54(9):2557-2567.

74. Hohmeier HE, Mulder H, Chen G, Henkel-Rieger R, Prentki M, Newgard CB. Isolation of INS-1derived cell lines with robust ATP-sensitive $\mathrm{K}+$ channel-dependent and -independent glucose-stimulated insulin secretion. Diabetes. 2000;49(3):424-430.

75. Park L, et al. Suppression of accelerated diabetic atherosclerosis by the soluble receptor for advanced glycation endproducts. Nat Med. 1998;4(9):1025-1031.

76. Rampersad SN. Multiple applications of Alamar Blue as an indicator of metabolic function and cellular health in cell viability bioassays. Sensors (Basel). 2012;12(9):12347-12360.

77. Brett J, et al. Survey of the distribution of a newly characterized receptor for advanced glycation end products in tissues. Am J Pathol. 1993;143(6):1699-1712. 